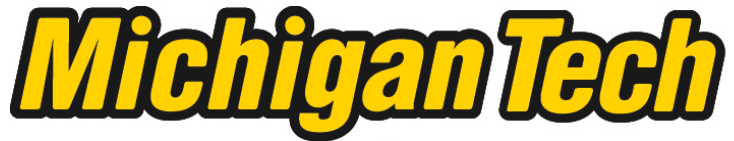 \\ Michigan Technological University Create the Future Digital Commons @ Michigan Tech
}

Dissertations, Master's Theses and Master's Reports - Open

Dissertations, Master's Theses and Master's

Reports

2011

Stochastic knock detection model for spark ignited engines

Yashodeep Lonari

Michigan Technological University

Follow this and additional works at: https://digitalcommons.mtu.edu/etds

Part of the Mechanical Engineering Commons

Copyright 2011 Yashodeep Lonari

\section{Recommended Citation}

Lonari, Yashodeep, "Stochastic knock detection model for spark ignited engines", Master's report, Michigan Technological University, 2011.

https://doi.org/10.37099/mtu.dc.etds/563

Follow this and additional works at: https://digitalcommons.mtu.edu/etds

Part of the Mechanical Engineering Commons 


\title{
Stochastic Knock Detection Model for Spark Ignited Engines
}

\author{
By \\ Yashodeep Lonari
}

A REPORT

Submitted in partial fulfillment of the requirements

for the degree of

MASTER OF SCIENCE IN MECHANICAL ENGINEERING

MICHIGAN TECHNOLOGICAL UNIVERSITY

2011 
This report "Stochastic Knock Detection Model for Spark Ignited Engines" is hereby approved in partial fulfillment of the requirements for the Degree of MASTER OF SCIENCE IN MECHANICAL ENGINEERING

DEPARTMENT: Mechanical Engineering - Engineering Mechanics

Report Advisor: Jeffrey D. Naber

Department Chair: William W. Predebon

Date:

Page 2 of 56 


\section{Contents}

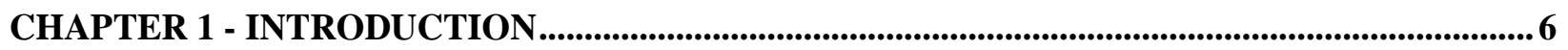

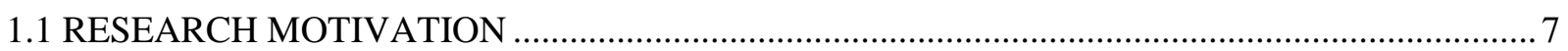

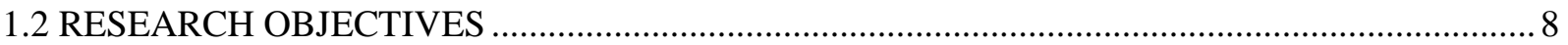

CHAPTER 2 - BACKGROUND AND PREVIOUS WORK.ERROR! BOOKMARK NOT DEFINED.

SUMMARY

CHAPTER 3 - STOCHASTIC KNOCK MODELS ................ERROR! BOOKMARK NOT DEFINED.

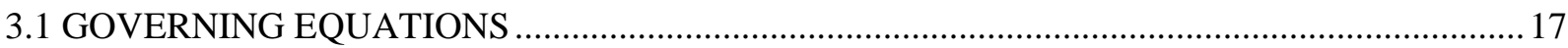

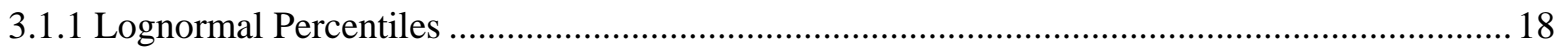

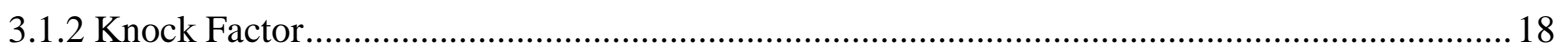

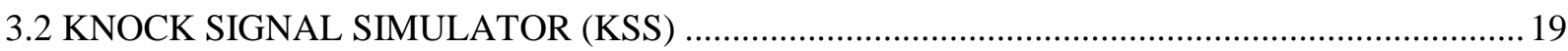

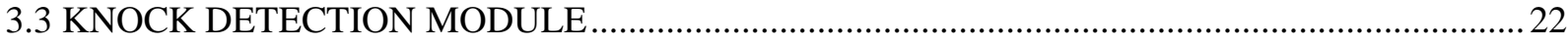

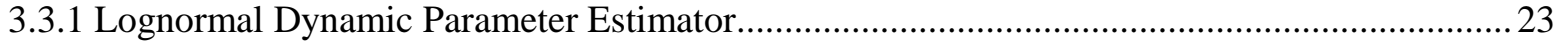

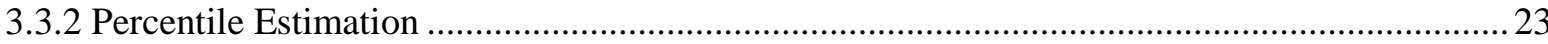

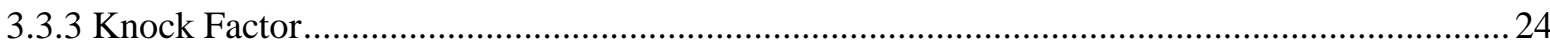

3.3.4 Filter Length Variation During Transient Operation ........................................................... 25

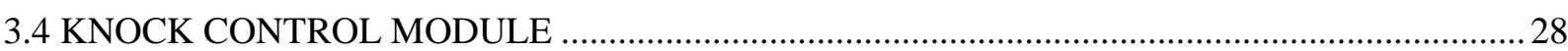

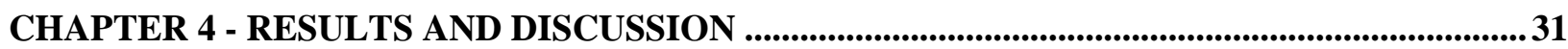

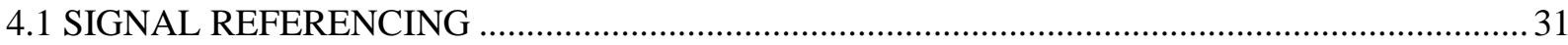

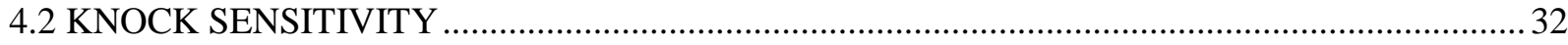

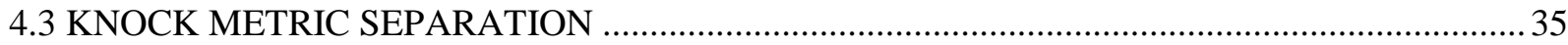

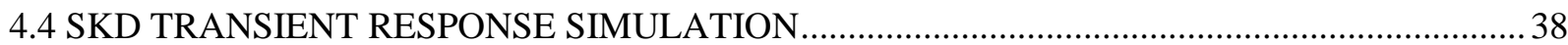

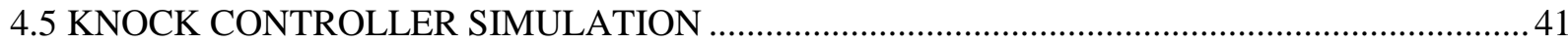

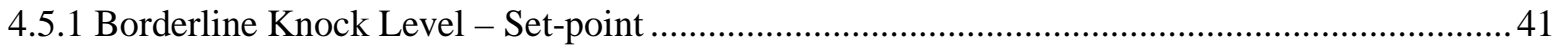

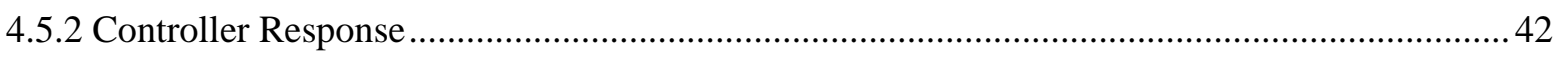

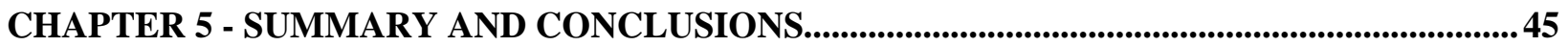


FIGURE 2-1: IN-CYLINDER PRESSURE TRACE FOR NON-KNOCKING AND A KNOCKING CONDITION [6]....................10

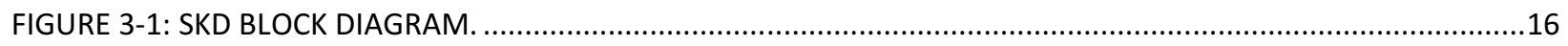

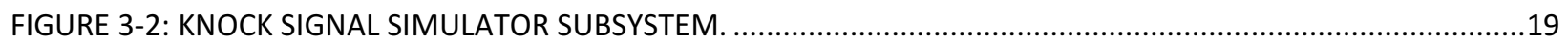

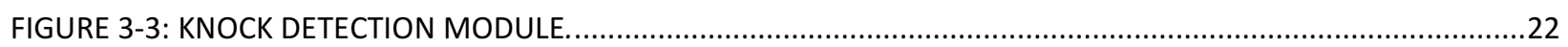

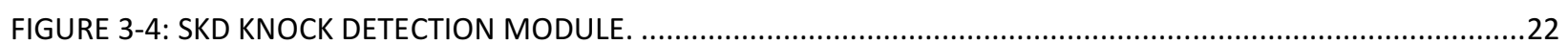

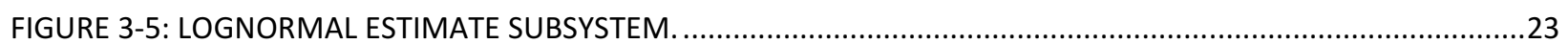

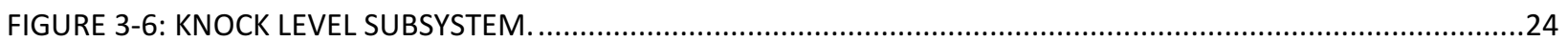

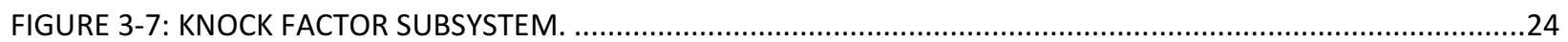

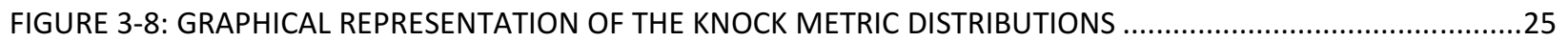

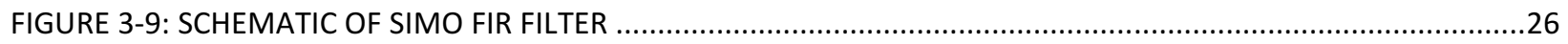

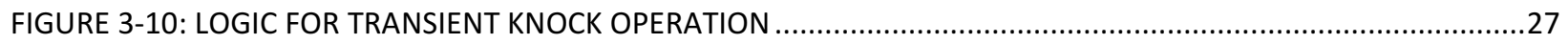

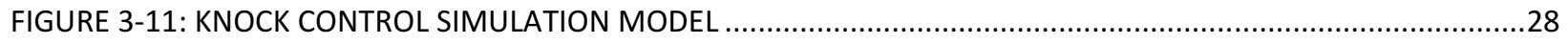

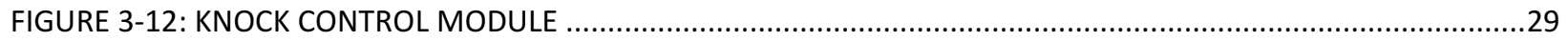

FIGURE 4-1: LOGNORMAL PDF OF THE SKD KNOCK METRIC AT 6 SPARK ADVANCEMENTS AND ENGINE

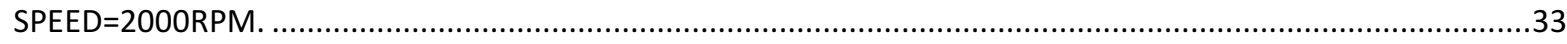

FIGURE 4-2: LOGNORMAL PDF OF THE CLASSIC KNOCK METRIC AT 6 SPARK ADVANCEMENTS AND ENGINE

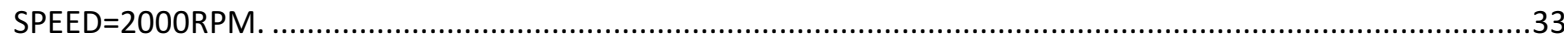

FIGURE 4-3: REFERENCE SIGNAL ANALYSIS FOR CYLINDER 7 FOR BL-3 TO BL+3: (A) ENGINE SPEED $=1000 R P M$, (B)

ENGINE SPEED=2000RPM, (C) ENGINE SPEED=3000RPM, (D) ENGINE SPEED=5000RPM .............................34

FIGURE 4-4 SEPARATION FACTOR WITH RESPECT TO BLO FOR CYLINDER 7 VS. BORDERLINE SPARK ADVANCE.........36

FIGURE 4-5 SEPARATION FACTOR WITH RESPECT TO BLO FOR CYLINDER 7 VS. BORDERLINE SPARK ADVANCE.........36

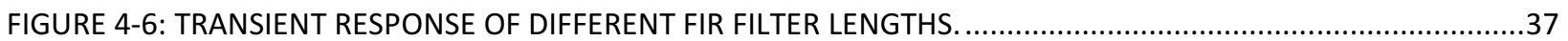

FIGURE 4-7: AVERAGE OF ESTIMATED LOGNORMAL $\sigma$ DURING TRANSIENT KNOCK OPERATION FROM LOW KNOCK LEVEL BLO $0^{\circ}$ TO HIGH KNOCK LEVEL BL $+10^{\circ}$

FIGURE 4-8: AVERAGE OF ESTIMATED LOGNORMAL $\sigma$ DURING TRANSIENT KNOCK OPERATION FROM LOW KNOCK LEVEL BLO $0^{\circ}$ TO HIGH KNOCK LEVEL BL+10 $0^{\circ}$

FIGURE 4-9: AVERAGE OF ESTIMATED LOGNORMAL $\mu$ DURING TRANSIENT KNOCK OPERATION FROM LOW KNOCK LEVEL BLO $0^{\circ}$ TO HIGH KNOCK LEVEL BL $+10^{\circ}$

FIGURE 4-10: AVERAGE OF ESTIMATED LOGNORMAL $\mu$ DURING TRANSIENT KNOCK OPERATION FROM LOW KNOCK LEVEL BLO $0^{\circ}$ TO HIGH KNOCK LEVEL BL+10 $0^{\circ}$

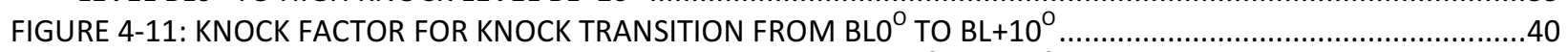

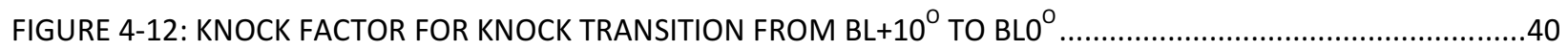

FIGURE 4-13: KNOCK FACTOR VARIATION AT BORDERLINE SPARK ADVANCE ....................................................41

FIGURE 4-14: KNOCK FACTOR IN STEADY STATE KNOCK CONTROL OPERATION. ................................................42

FIGURE 4-15: CONTROLLED SPARK TIMING AT BORDERLINE KNOCK LEVEL $\left(B L 0^{\circ}\right)$...............................................43

FIGURE 4-16: BOX PLOT COMPARING DISTRIBUTION KNOCK INTENSITY KI SPREADS WITH CONTROLLER ENABLED

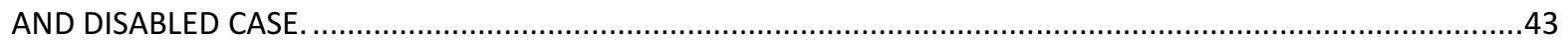

FIGURE 4-17: SIMULATED TRANSIENT SPARK TIMING RESPONSE OF KNOCK CONTROLLER AT 2000RPM AND WOT44

FIGURE 4-18: SIMULATED CONTROLLER RESPONSE TO A STEP INPUT OF BL $+3^{\circ}$ AT 2000RPM AT WOT ....................45

Page 4 of 56 


\section{ABSTRACT}

This report presents the development of a Stochastic Knock Detection (SKD) method for combustion knock detection in a spark-ignition engine using a model based design approach. Knock Signal Simulator (KSS) was developed as the plant model for the engine. The KSS as the plant model for the engine generates cycle-to-cycle accelerometer knock intensities following a stochastic approach with intensities that are generated using a Monte Carlo method from a lognormal distribution whose parameters have been predetermined from engine tests and dependent upon spark-timing, engine speed and load. The lognormal distribution has been shown to be a good approximation to the distribution of measured knock intensities over a range of engine conditions and spark-timings for multiple engines in previous studies. The SKD method is implemented in Knock Detection Module (KDM) which processes the knock intensities generated by KSS with a stochastic distribution estimation algorithm and outputs estimates of high and low knock intensity levels which characterize knock and reference level respectively. These estimates are then used to determine a knock factor which provides quantitative measure of knock level and can be used as a feedback signal to control engine knock. The knock factor is analyzed and compared with a traditional knock detection method to detect engine knock under various engine operating conditions.

To verify the effectiveness of the SKD method, a knock controller was also developed and tested in a model-in-loop (MIL) system. The objective of the knock controller is to allow the engine to operate as close as possible to its border-line spark-timing without significant engine knock. The controller parameters were tuned to minimize the cycle-to-cycle variation in spark timing and the settling time of the controller in responding to step increase in spark advance resulting in the onset of engine knock. The simulation results showed that the combined system can be used adequately to model engine knock and evaluated knock control strategies for a wide range of engine operating conditions.

Page 5 of 56 


\section{CHAPTER 1}

\section{INTRODUCTION}

Engine knock is an important combustion phenomenon that sets an upper limit on the ability to maximize the engine power and fuel efficiency produced by a spark-ignition (SI) engine under given operating conditions [1]. Under combustion knock constrain, the engine cannot operate at its optimal spark timing because the engine's knock limited spark advance occurs before optimal combustion phasing. Advancing spark timing further would result in engine knock severe enough to result in unacceptable combustion generated noise, a decrease in combustion efficiency, and/or can cause engine damage. To limit knock when it is detected, a commonly used control approach is to retard the spark timing which phases combustion later in the engine cycle and lowers the peak pressures and temperatures within the combustion chamber [1].

Extensive research material is available that focuses on detecting and controlling knock by characterizing engine knock intensities, signal processing, and development of quantitative knock metrics including recent work related to the method discussed here [2-4]. The goal of this study is to develop a knock detection algorithm such that the output of this algorithm can be used by closed-loop control algorithms to operate the engine as close as possible to the knock limited optimal spark timing (borderline knock spark timing). We propose a method termed Stochastic Knock Detection (SKD) [5] to estimate knock levels using a statistical estimation approach in which the separation between knocking levels can be increased while the latency in the estimator can be controlled and minimized. Another goal of this method was to minimize the calibration required and to provide an integrated sensor and background signal level referencing. This estimator would then enable a controller to find the borderline spark timing quickly and maintain this level while the engine operates in steady state conditions in order to maximize efficiency and reduce fuel consumption.

Presently, in many systems, the spark timing control of internal combustion engines is deterministic in nature because of the assumption that if knock occurred in the current cycle, then Page 6 of 56 
it will also occur in the next cycle unless the spark is immediately retarded. These methods do not utilize stochastic information for determination of control parameters. This can result in the engine being continuously taken in and out of knock if proportional control is used or it can limit dynamic response if integral gain is applied, rather than operating smoothly at the desired point. If a control strategy is used for borderline knock control utilizing the stochastic properties of the knock intensity as the feedback signal, the control system would be able to operate the engine at its borderline knock limit smoothly.

The focus of this study and work is to account for the stochastic nature of knock using knock intensity distributions modeled as lognormal [6]. This approach uses a calibrated number of knock intensities (KI) from previous firing events, thus forming a dataset for the statistical analysis. The distribution lognormal mean and standard deviation of this dataset are estimated in real-time during engine operation using a weighted FIR filter. Knock levels at high and low percentiles of this dataset are estimated and combined to form a knock factor from these parameters to predict a reference level of combustion knock.

\subsection{RESEARCH MOTIVATION}

The motivation is to improve engine efficiency by achieving steady spark timings close to optimal spark timings over a wide range of engine operating conditions, such that knock intensities are at acceptable levels, termed borderline knock level, which won't damage engine components. Engine efficiency can be achieved by developing knock detection and control strategy with a stochastic approach as opposed to a deterministic approach used by existing control strategies, thus improving engine efficiency.

Knock detection with pressure transducers is very effective but these sensors are expensive for production engines. The goal of this study is to provide an alternative knock detection strategy which uses cheap sensors, like an accelerometer or ionization based measurements.

With an accelerometer as a knock sensor, measured knock intensity is affected by varying background noise level due to valve dynamics, piston slap, etc; this background noise is a function of engine speed, which gets induced in measured knock intensities at higher engine speeds as both knock and background noise have the same frequency bandwidth. The Page 7 of 56 
background noise affects the signal-to-noise ratio at higher engine speeds, one method to address this issue is to normalize knock intensity measured over a firing crank angle window with a reference measured accelerometer signal intensity over non-firing crank angle window. This method is termed as dual-window referencing which is difficult to realize with variable valve cam-timing (VCT) being introduce to improve engine performance. With varying valve timing, the reference window position with respect to crank angle needs to change as speed/load changes, and engines with more cylinders make it difficult to calibrate a reference window which is free from firing event.

This leads to the development of single window methods for knock detection. In these methods running average of knock intensity from firing events is used as reference. But based on special logic, it determines on every firing event whether to include knock intensity signal in the reference or not $[7,8]$. This requires calibration of the separation logic and often separation of events is not perfect, such that the reference method includes light combustion knock. Similar processes for referencing/normalization are required for ionization based methods [9].

Solutions to the challenges discussed above are provided by the knock detection and control strategy proposed in this report.

\subsection{RESEARCH OBJECTIVES}

This report includes the development and simulation of a stochastic knock model to estimate combustion knock levels using single window referencing methods for accelerometer based knock detection.

A model based on statistical techniques to characterize the knock metrics measured by an accelerometer to predict knock level for various engine speeds using Ford V8 engine data was developed and implemented in SIMULINK. This model was further used as a simulation tool to conduct a detailed analysis of various knock metrics, comparing performance of the SKD method with existing single window knock detection methods.

Page 8 of 56 
The research objectives are:

- Using data from the 5.7L V8 for a range of non-knocking to knocking conditions, engine speeds and other factors, examine methods for single window referencing.

- Examine existing single window and MTU dynamic stochastic probability distribution function (pdf) model to determine a referencing method to characterize the non-knocking level.

- Examine lower pdf (e.g., $25^{\text {th }}$ ) percentiles estimates as determined from stochastic pdf model and compare to knocking levels.

- Develop quantitative metrics for evaluation of SKD in comparison with an existing single window referencing technique.

- Development of a knock control module to demonstrate knock control using the SKD method in steady state and transient operating conditions. 


\section{CHAPTER 2}

\section{BACKGROUND AND PREVIOUS WORK}

Combustion knock is one of the primary factors limiting performance of SI engines. Knock occurs due to auto-ignition of unburnt air/fuel mixture in pockets in front of the turbulent flame front, causing a rapid release of energy. This rapid release leads to high local pressures and develops pressure waves inside the engine cylinder. Unwanted engine vibrations and noise is caused as resonance modes of the engine block are excited by the pressure waves [1]. These pressure waves or shock waves are very harmful, if the engine continues to operate in these extreme conditions, engine components can be severely damaged. Additionally, due to rapid energy release, in-cylinder temperatures go up causing increased energy loss due to heat transfer and thus lowering engine efficiency. The frequency spectrum of these waves is from 5 to $15 \mathrm{kHz}$ at lower engine speeds and from 5 to $20 \mathrm{kHz}$ at higher speeds [6].
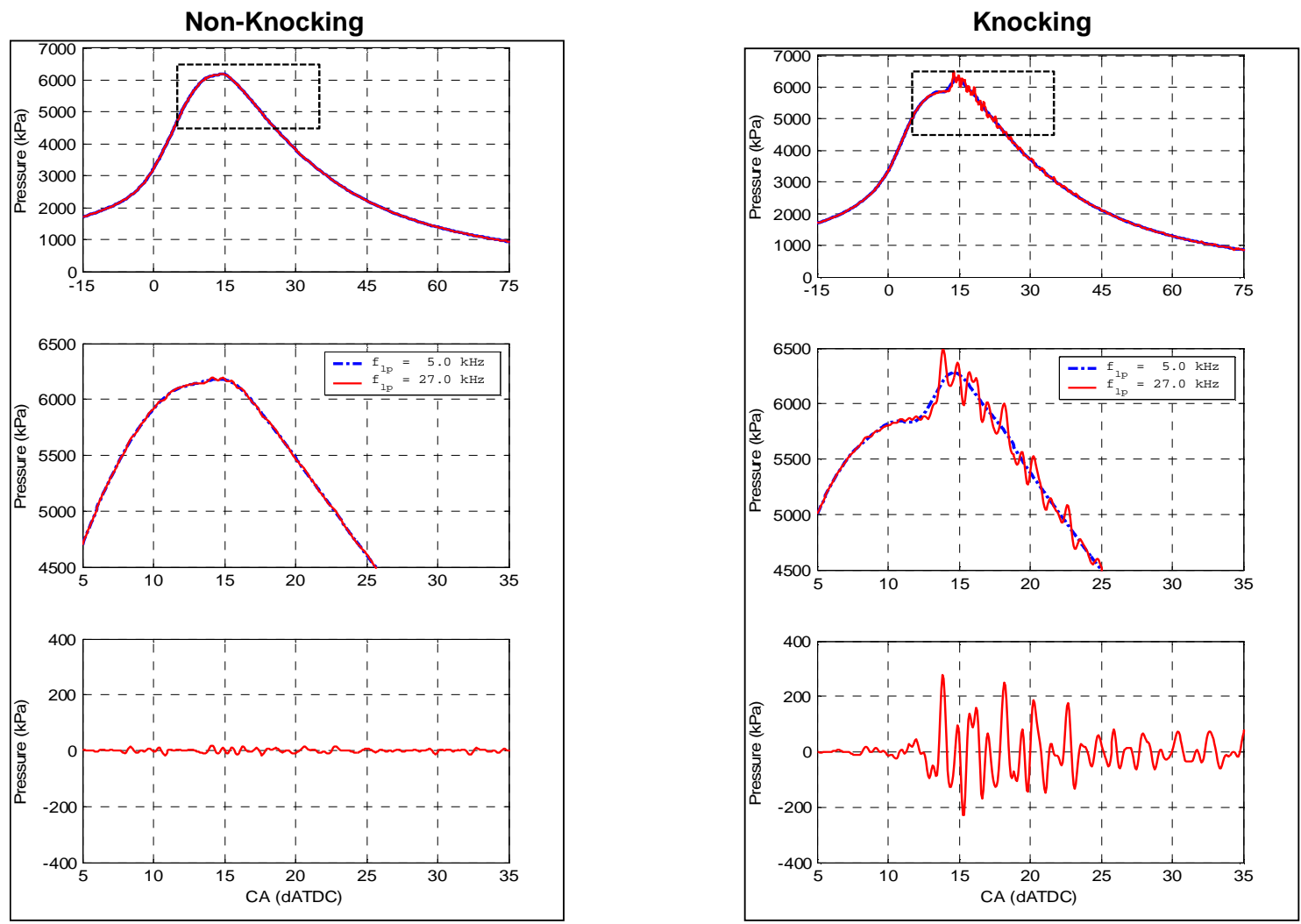

Figure 2-1: In-cylinder pressure trace for non-knocking and a knocking condition [6]. Page 10 of 56 
Figure 2-1 shows in-cylinder pressure traces for knocking and non-knocking cases obtained from a Ford V6 engine at $2500 \mathrm{rpm}$ and wide open throttle. Raw data of the in-cylinder pressure trace is plotted against engine position in crank angle degrees in the top plot. The middle plot is a zoomed in version of the top plot and illustrates oscillations in pressure trace during knocking. The bottom plot is obtained by band-pass filtering the pressure signal with a frequency band of 5 to $27 \mathrm{kHz}$ [6]. Comparing the bottom plots from Figure 2-1, knock data associated with the high frequency component is clearly seen after band-pass filtering the low frequency components due to compression, heat release and expansion.

Knock detection and control has been studied to a great extent. Some of the early work and more fundamental investigations are published in references [10-15]. The findings from these investigations are applied to control knock in modern day engine management systems using knock sensors mounted on the engine block at suitable locations. Commonly, these sensors are called accelerometers and consist of a piezoelectric crystal around which a wire is coiled. When stress is applied to the crystal a voltage is produced. As the engine vibrates during combustion, stress is applied to the sensor which is proportional to the intensity of the vibration, which in turn produces a proportional output voltage from the sensor. Signal processing techniques are applied to this signal and knock intensities are generated, one such signal processing technique was discussed earlier.

Knock sensing using in-cylinder pressure base measurements obtained by using pressure transducer are very accurate and robust, but these sensors are expensive and require major modification to the engine for mounting, thus making them unsuitable to be used on most production engines. They are, however, often and most typically used in research, development and calibration as a reference for validation of other cost effective techniques that are being developed. Pressure transducers used for in-cylinder measurements use piezoelectric material like quartz elements because of the high dynamic pressures. When a pressure is applied quartz generates a small charge (in units of picoCoulomb $[\mathrm{pC}]$ ), which is proportional to the applied pressure. With the help of charge amplifiers this charge is converted to a voltage. The charge amplifiers utilize high gain voltage amplifiers with high insulation resistance, thus preventing charge leakage.

Page 11 of 56 
Even with significant development in pressure sensors for in-cylinder measurements, they remain uneconomical to be used for production engines. An ion sensing techniques are being developed as a potential alternative to pressure transducers. An ion sensor has an electric probe in the combustion chamber which is a positively charged electrode. During combustion, due to chemical and thermal ionization of the working fluid, positively and negatively charged free ions are generated. The negative ions are attracted towards the positive electrode, while positive ions move towards the chamber walls, thus setting up an ion current flow between the sensor (positive electrode) and ground (combustion chamber walls). This current is then measured by passing through a resistor to obtain a voltage drop across the resistor. The voltage is then amplified and used as sensor output.

Further, application of knock sensor, signal processing and control to engine management system can be found in $[16,17]$. Various knock intensity signal processing techniques and metrics from in-cylinder pressure measurements have been proposed and studied [3, 18]. Burnt et al. [3] developed a detailed method to determine knock intensity based on band-pass filtered peak pressure trace over a crank-angle combustion window. Millo and Ferraro [2] compared different techniques for detection of engine knock. Both pressure based and accelerometer based measurements were analyzed. The following three knock intensity metrics were evaluated for both types of measurements: 1) Maximum peak-to-peak amplitude of band-pass filtered signal; 2) Mean square of band-pass filtered signal; 3) Integrating absolute value of first derivative of band-pass filtered signal. They evaluated the sensitivity of these metrics to knock levels at increasing spark advance and background noise due to valve dynamics and piston slap as engine speed changes. They concluded that all metrics for knock detection were reliable and consistent with each other, however, for accelerometer based measurements, signal-to-noise ratio decreases at high engine speeds because of increased background noise (due to valve dynamics, piston slap etc.). To account for varying background noise levels Torno, $\mathrm{O}$ et. al. [7] patented a mechanism in which accelerometer based measurements are normalized by a reference value which is measured during a separate crank-angle window preceding the knock window. This method requires the calibration of a second window for each speed/load point and finding a window without excessive noise from valve closure which becomes more difficult for high cylinder count

Page 12 of 56 
engines. Additionally, in the case of variable cam timing (VCT) engines, the position now must be calibrated in conjunction with the engine calibration for cam phasing.

Engine knock is difficult to predict as there is cycle-to-cycle variation in combustion of incylinder charge even if engine operation conditions, including engine load, speed, injection duration, spark advance and valve timings, are held constant. Three main factors that cause this variation are: 1) in-cylinder gas turbulence motion, turbulent flow by definition is chaotic and causes rapid variation in pressure and velocity of the flow; 2) variation in the amount of residual gases; 3) air which directly affects the rate of combustion and energy release, 4) variation in spatial distribution of air, residuals, and fuel leads to variation in concentration of in-cylinder charge thus affecting flame front development and propagation [19]. Due to these reasons engine knock is characterized as a random process and is stochastic in nature.

Leppard [20] reported that knock intensity distributions were non-Gaussian in nature. They characterized the knock intensities using cumulative distribution functions but did not examine their non-Gaussian nature.

Distributions of knock intensity measured from band-pass peak knock cylinder pressure were characterized using Gamma distribution by Sinnerstad [21]. She also evaluated other types of distributions, normal, chi-square, and weibull, with a sample size of 100 cycles. Distribution fits were evaluated and due to skewness of data normal distribution was eliminated. Further simplicity of methods to fit the data was also considered, gamma distribution was then selected as best to describe the distribution of peak pressures. By applying the maximum likelihood estimation, she determined distribution parameters, and then the confidence interval for mean knock intensity was estimated using these distribution parameters.

Naber et al. [6] studied and characterized engine knock intensity using both in-cylinder pressure and block mounted accelerometer-based measurements on a V6 engine. The knock intensity was obtained by the signal processing method of band-pass filtering, rectifying, windowing, and integrating the measured signals. They showed that lognormal distributions were a good fit to measured knock distributions for various engine speeds, loads, cam timings, and knock levels, and captured the skewness and peakness of the distribution. They also examined correlation 
between the accelerometer intensity metric and the reference in-cylinder pressure intensity metric. They concluded that a sample size of 100 combustion events was sufficient to determine within $\pm 10 \%$ of the 95 th percentile knock intensity based upon the individual expected variability of the mean and standard deviation of the logarithm of sampled values. They also pointed out the necessity to normalize metrics, as the correlation between accelerometer and pressure intensities improves with higher knock levels.

Abhijit and Naber [22] extended this analysis to ionization-based knock intensities and showed that a lognormal distribution provided excellent representation and fit to the knock distributions for both the in-cylinder pressure and ion signal knock intensities (coefficient of determination $\mathrm{R}^{2}$ $>0.8$ were obtained) over a wide range of operating conditions on an expanded V8 engine dataset and a reduced I4 engine dataset. In addition, they found that because of the location dependence response of the pressure and ion signal-based knock intensities, cycle-to-cycle correlations were poor, but by utilizing statistical methods they showed that both exhibited similar responses to knock level changes.

Zhu et al. [23] used in-cylinder ionization measurements to determine knock intensities to develop stochastic knock limit feedback control. They used a non-linear map that transformed knock intensity distribution to a Gaussian distribution. Gang $\mathrm{Wu}$ [24] proposed a real-time statistical method to determine engine knock threshold by using lognormal fit to knock intensity distribution. He used the property of converting lognormal distribution to normal distributions by taking the log of the sample values. Then with student's t-distribution estimate knock threshold value for a user defined knock probability.

Peyton et al. [25] developed a knock control algorithm based on cumulative summation of knock event occurrences at a target knock level. They provided a comparison of their knock control algorithm with a deterministic control algorithm, showing improved performance in terms of ability to operate at steady spark timing, which is within $+/-0.5^{\circ}$ of target borderline spark timing. In their work, they have focused on control evaluation; however, limited details are available on how knock is detected under various operating conditions. Moreover, their control response from no-knock level to borderline (BL) knock level is slow, and took 450 cycles to reach $+/-0.5^{\circ}$ of target borderline advance timing.

Page 14 of 56 
Naber and Rajagopalan [5] developed a dynamic estimation method applicable to real-time detection using a two-parameter lognormal distribution to predict knock levels at one or more percentile levels (e.g, $25^{\text {th }}$ and $95^{\text {th }}$ ) with tunable response and separation capability by varying the estimator length and weighting function. Polonowski [26] used output from this dynamic estimation model to develop an integral-derivative type of knock control algorithm. He was able to gain steady state knock control within $\pm 1^{\circ}$ of target borderline knock but reported errors in knock level estimation during transient operating conditions.

\section{Summary}

Engine knock is undesirable leading to increased fuel consumption, damage to engine components and noisy operation of engine causing consumer dissatisfaction. Thus, combustion control is a very important part of the engine management system. Knock sensing with a pressure transducer is very reliable but economically unfeasible for production engines. Thus, it's important to develop methods to detect knock with cheaper alternatives like accelerometers and ion sensing techniques. Further, accelerometer based measurements show a dramatic reduction in signal-to-noise ratio as background noise from valve dynamics, piston slap etc. increase at high engine speeds. Thus, for accelerometer based measurements a mechanism is needed to normalize the effect of change in background noise.

Combustion knock is stochastic in nature, but current knock detection and control systems apply deterministic approach that, if knock occurs in one firing event, the next firing event will also be a knocking event. Naber et. al. [6] showed lognormal distribution is a good fit to accelerometer based knock intensity distribution, thus providing the ability to account for the stochastic nature of engine knock. Naber and Rajgopalan [5] developed a real time knock level estimation model based on the characterization of knock intensity distribution as lognormal. Abhijit and Naber extended a similar analysis to ion based knock intensities. Polonowski [26] evaluated stochastic knock detection and control on a Ford-I4 engine with accelerometer based sensing. He was able to gain steady state knock control with $\pm 1^{\circ}$ of target borderline knock but reported a lag in knock level estimation during transient operating conditions. The details, including specifics of the estimator, characterization of the separation and response, and the extension of this development, are covered in this work.

Page 15 of 56 


\section{CHAPTER 3}

\section{STOCHASTIC KNOCK MODELS}

The stochastic approach to detect engine knock proposed in this work is termed as Stochastic Knock Detection (SKD) method [5]. SKD is designed to take the measured cycle to cycle knock intensities from accelerometers, in-cylinder pressure transducers, ionization signals or other knock intensities from a cylinder and determine a referenced level of knock severity. SKD does this by comparing the estimated lognormal high and low percentiles of knock intensity distribution obtained from a given number of consecutive knock intensities (KI) through the use of a calibrated knock factor. The knock factor provides a normalized value of knock propensity level that can be used in a number of knock control methods. It is important to note that this method, by design and without further complex logic, integrates a referencing method from the statistical characteristics to normalize the knock intensity metrics for varying background noise [2] and sensor gain which is a critical aspect when using both accelerometer and ion based measures. The overall execution of SKD is shown in Figure 3-1. SKD comprises of two main modules namely "Knock Signal Conditioning" and "Knock Detection Module." these are implemented using MathWorks SIMULINK ${ }^{\mathrm{TM}}$, which will be discussed in subsequent sections. The "Knock Signal Conditioning" in the simulation environment is modeled as "Knock Signal Simulator"

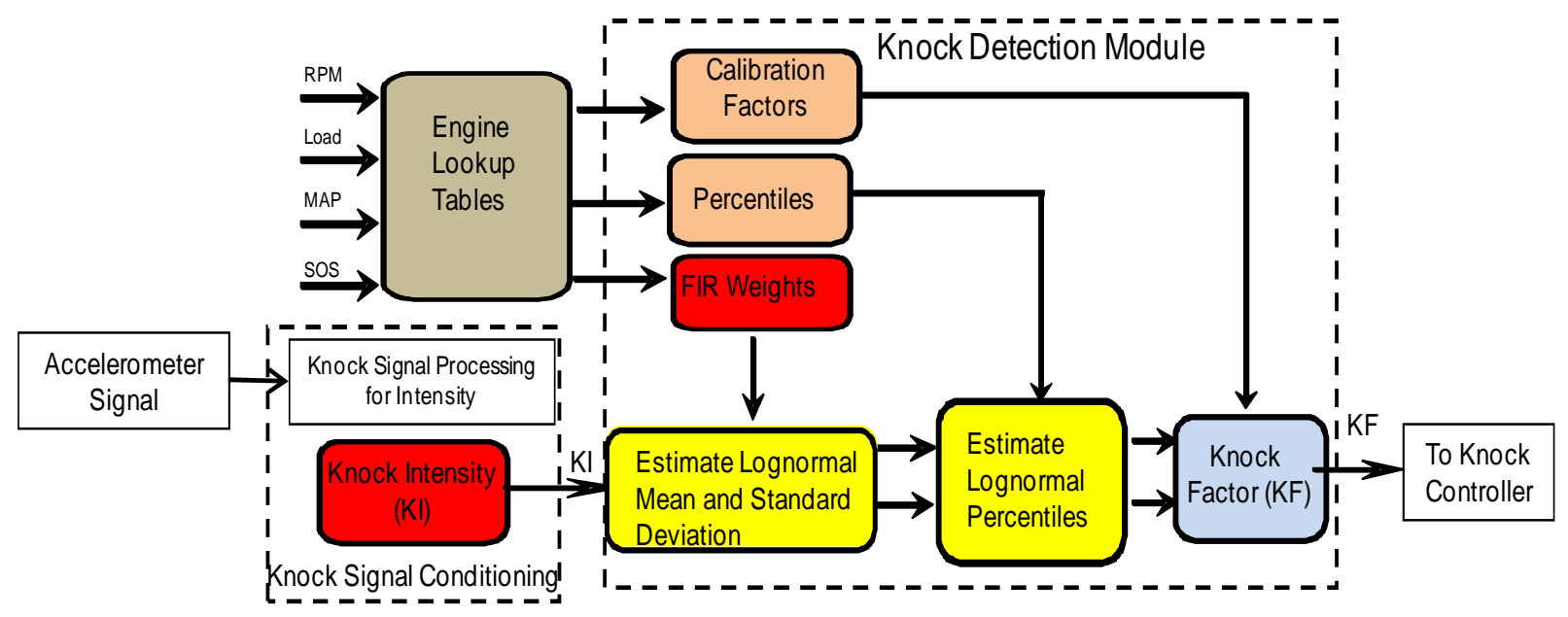

Figure 3-1: SKD block diagram.

Page 16 of 56 


\subsection{GOVERNING EQUATIONS}

The lognormal $\widehat{\mu}$ and $\widehat{\sigma}^{1}$ are variables used to estimate the shape of the lognormal distribution for a set of data points (xj) and are the mean and standard deviation of $\mathrm{x}$. Equations 1 and 2 are used to compute the lognormal $\widehat{\mu}$ and population $\widehat{\sigma}[2,24]$.

$$
\begin{gathered}
\hat{\mu}=\frac{\sum \ln \left(x_{j}\right)}{n} \\
\widehat{\sigma}=\sqrt{\frac{\sum\left(\ln \left(x_{j}\right)-\hat{\mu}\right)^{2}}{n-1}}
\end{gathered}
$$

where $x$ is a set of KI data points in the distribution and $n$ is the number of data points.

In the SKD method, KI's represent the " $x$ " data set and " $n$ " represent the number of cycles. Upon inspection of these equations, dynamic estimates of Equations 1 and 2 can be implemented using a digital FIR filter with weights equal to $b_{j}=1 / n$ or other sets of coefficients whose sum is 1. This insight is important because digital FIR filters can be efficiently implemented into software and their response times can be tuned to meet a user's needs. The response time of the SKD estimates of $\hat{\mu}_{\mathrm{w}}$ and $\widehat{\sigma}_{\mathrm{w}}$ can be shortened by reducing the number of coefficients or weighting the filter coefficients towards the most recent data points. Equations 3 and 4 represent the weighted FIR format for lognormal $\widehat{\mu}$ and $\widehat{\sigma}[27]$ (the derivation is shown in Appendix A).

$$
\begin{gathered}
\hat{\mu}_{w}=\sum b_{j} \cdot \ln \left(x_{j}\right) \\
\widehat{\sigma}_{w}^{2}=\frac{n}{(n-1)}\left(\sum b_{j} \ln \left(x_{j}\right)^{2}-\hat{\mu}_{w}^{2}\right) \\
b(j)=\frac{1+(n-j)}{\sum_{1}^{n=30}(j)}
\end{gathered}
$$

Equation 3

Equation 4

Equation 5

where,

$j$ goes from 1 to $n$,

$n$ is the number of data point, $\sum b_{j}=1$

\footnotetext{
${ }^{1}$ Note $\widehat{\mu}$ and $\widehat{\sigma}$ are estimates of population mean $\mu$ and standard deviation $\sigma$. In this report the population $\mu$ and $\sigma$ of knock intensity distribution under given engine operating condition are obtained from experimental data and are thus known.

Page 17 of 56
} 


\subsubsection{Lognormal Percentiles}

Low and high lognormal percentiles are estimated using equation 6.

$$
K I(z)=e^{\left(\left[\operatorname{erfinv}\left(\frac{z}{50}-1\right) \cdot \widehat{\sigma}_{w} \cdot \sqrt{2}\right]+\widehat{\mu}_{w}\right)}
$$

Equation 6

Where erfinv is the inverse error function and $z$ is the desired percentile from 0 to 100.

In order to process the percentile values efficiently in an embedded control system, the inverse error functions were computed at percentile intervals of $5 \%$ and entered into a lookup table. The lookup table was generated using equation 7 and the resulting percentile equation is given by equation 8 [28]. Mean and standard deviation in equation 6 and 8 are known and are estimated using equations 3,4 , and 5 .

$$
\begin{array}{r}
\xi=\operatorname{erfinv}\left(\frac{z}{50}-1\right) \cdot \sqrt{2} \\
K I(z)=e^{\left(\xi \cdot \widehat{\sigma}_{w}+\widehat{\mu}_{w}\right)}
\end{array}
$$

Equation 7

Equation 8

\subsubsection{Knock Factor}

The knock factor is a scalar variable used to measure the separation between the high and low knock intensity percentiles. The separation between the two percentiles can be measured both by a ratio or subtracted difference. Therefore, a generic user adjustable format for the knock factor (equation 9) was chosen with five adjustable calibration coefficients A, B, C, D, and E that can be changed during simulation/test runs for evaluation of each metric.

$$
K F_{j}=\frac{A * K I(\text { high percentile })+B * K I(\text { low percentile })}{C * K I(\text { high percentile })+D * K I(\text { low percentile })+E} \quad \text { Equation } 9
$$

This format was chosen because it allows the user to select different knock factors while development is being done without having to modify the Engine Control Unit (ECU) control strategy. The knock factors resulting for common sets of calibration coefficients for percentile levels of $95 \%$ and $25 \%$ are given in Table 1 . In this work, analysis of $K I 95 / K I 25$ is presented as it has better behavior compared to other knock factors based on a study by [26].

Page 18 of 56 
Table 1: Knock factor formats with high percentile of 95 and low percentile of 25 percent.

\begin{tabular}{|c|c|c|c|c|c|c|}
\hline Format & A & B & C & D & E & Knock Factor (KF) \\
\hline 1 & 1 & 0 & 0 & 1 & 0 & $\frac{K I 95}{K I 25}$ \\
\hline 2 & 1 & -1 & 0 & 0 & 1 & $K I 95-K I 25$ \\
\hline 3 & 1 & -1 & 0 & 1 & 0 & $\frac{K I 95-K I 25}{K I 25}$ \\
\hline 4 & 0 & 1 & 1 & 0 & 0 & $\frac{K I 25}{K I 95}$ \\
\hline 5 & 1 & -1 & 1 & 0 & 0 & $\frac{K I 95-K I 25}{K I 95}$ \\
\hline
\end{tabular}

\subsection{KNOCK SIGNAL SIMULATOR (KSS)}

Knock Signal Simulator (KSS) was created to generate cycle to cycle accelerometer intensities following a lognormal distribution as a lognormal distribution has been shown to model the cycle to cycle occurrence of engine knock [6], [26]. The simulator uses look-up tables "KI Mean" and "KI Standard Deviation" of lognormal $\mu$ and $\sigma$ to generate KI's that follow a lognormal distribution. The simulator is based on equation 10. KSS is built as shown in the SIMULINK block diagram in Figure 3-2.

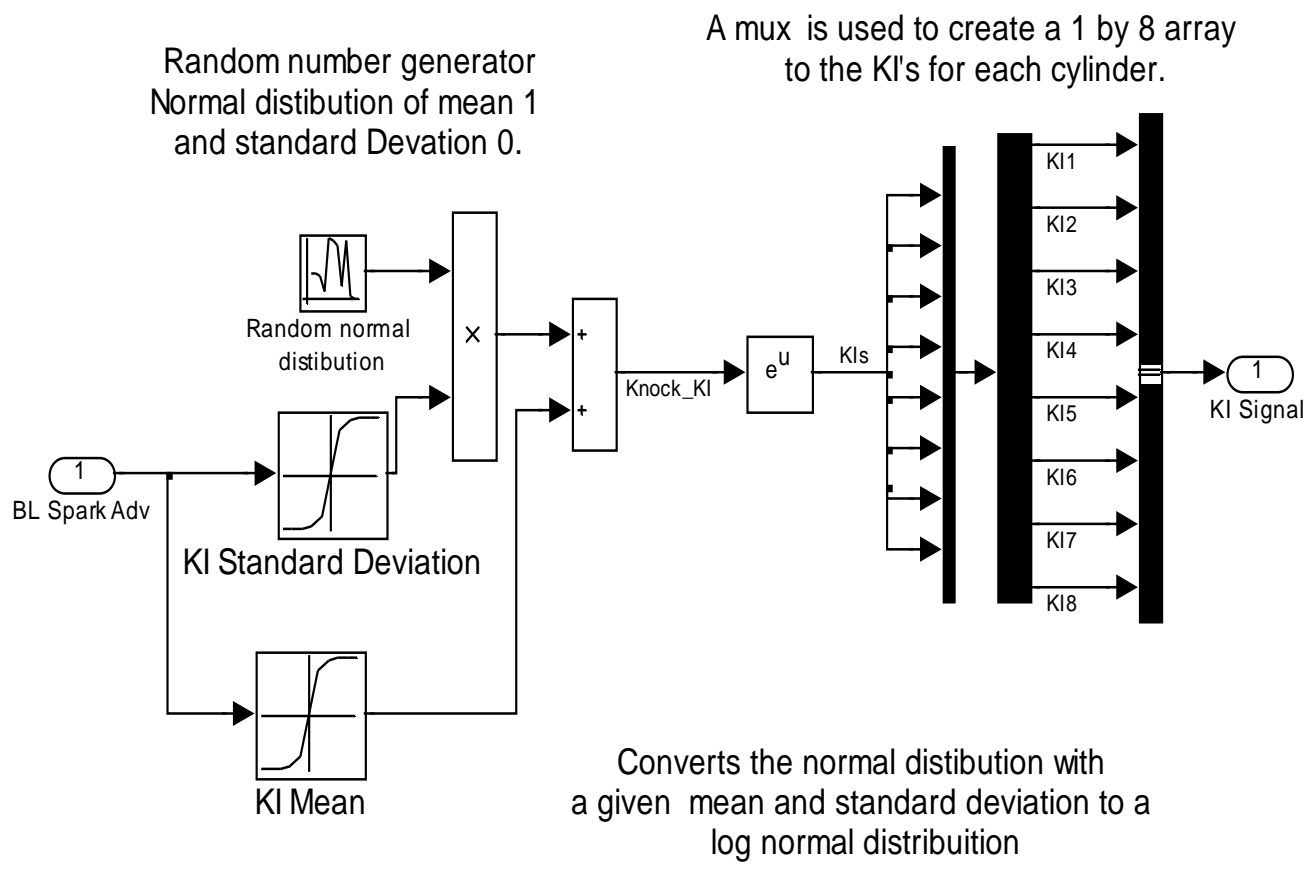

Page 19 of 56

Figure 3-2: Knock Signal Simulator Subsystem. 
This simulation is only for one condition where the KI distribution is mapped as a function of spark advance which are obtained from experimental data refer Table 3 and 4.

$$
K I^{\prime} S=e^{\mu+(\sigma * \text { Normal_distibution }(0,1))}
$$

Equation 10

Table 2: Ford V8 engine specifications.

\begin{tabular}{|l|l|}
\hline Engine Type & 4-Stroke, PFI, SI \\
\hline Cylinders & V8 \\
\hline Displacement (cm3) & 5400 \\
\hline Bore x Stroke (mm) & $90.1 \times 105.9$ \\
\hline Compression Ratio & $9.8: 1$ \\
\hline
\end{tabular}

Table 3: Mean Knock Intensity from Ford V8 engine cylinder 7 data.

\begin{tabular}{|c|c|c|c|c|c|c|}
\hline \multirow{2}{*}{\multicolumn{2}{|c|}{ KI Mean $(\boldsymbol{\mu})$}} & \multicolumn{5}{|c|}{ Engine Speed (RPM) } \\
\hline & & 1000 & 2000 & 3000 & 4000 & 5000 \\
\hline \multirow{7}{*}{ 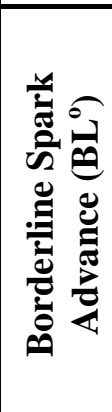 } & -3 & -5.27838 & -4.00448 & -3.47866 & -2.94228 & -2.44166 \\
\hline & -2 & -5.22125 & -3.9752 & -3.49745 & -2.91568 & -2.42855 \\
\hline & -1 & -5.05698 & -3.91619 & -3.47767 & -2.90976 & -2.40363 \\
\hline & 0 & -4.5233 & -3.85002 & -3.4224 & -2.89017 & -2.44552 \\
\hline & 1 & -4.11691 & -3.71964 & -3.3068 & -2.87795 & -2.46747 \\
\hline & 2 & -3.75554 & -3.49883 & -3.18778 & -2.81058 & -2.47476 \\
\hline & 3 & & -3.21896 & -3.00702 & -2.72329 & -2.3858 \\
\hline
\end{tabular}

Table 4: Knock Intensity Standard Deviation from Ford V8 engine cylinder 7 data.

\begin{tabular}{|c|c|c|c|c|c|c|}
\hline \multirow{2}{*}{\multicolumn{2}{|c|}{$\begin{array}{l}\text { KI Standard } \\
\text { Deviation }(\sigma)\end{array}$}} & \multicolumn{5}{|c|}{ Engine Speed (RPM) } \\
\hline & & 1000 & 2000 & 3000 & 4000 & 5000 \\
\hline \multirow{7}{*}{ 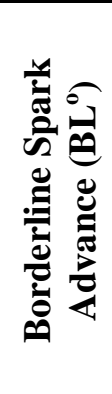 } & -3 & 0.2973179 & 0.1727507 & 0.180582 & 0.175085 & 0.195199 \\
\hline & -2 & 0.32611948 & 0.1923307 & 0.189993 & 0.187488 & 0.209737 \\
\hline & -1 & 0.42062493 & 0.2144286 & 0.208845 & 0.199829 & 0.202505 \\
\hline & 0 & 0.48766796 & 0.2406017 & 0.249366 & 0.191636 & 0.230862 \\
\hline & 1 & 0.5316205 & 0.3137609 & 0.392482 & 0.217127 & 0.230966 \\
\hline & 2 & 0.56814073 & 0.4492888 & 0.441939 & 0.256358 & 0.311494 \\
\hline & 3 & & 0.5437456 & 0.538889 & 0.311586 & 0.335584 \\
\hline
\end{tabular}


The knock intensity mean $(\mu)$ and standard deviation $(\sigma)$ values in Table 3 and 4 , respectively are obtained from data tests on a V8 engine, the specifications are given in Table 2. The engine was operated at WOT for engine speed from 1000-5000rpm and borderline spark advance from borderline minus 3 degrees crank angle $\left(\mathrm{BL}-3^{\circ}\right)$ to borderline plus 3 degrees crank-angle $\left(\mathrm{BL}+3^{\circ}\right)$.

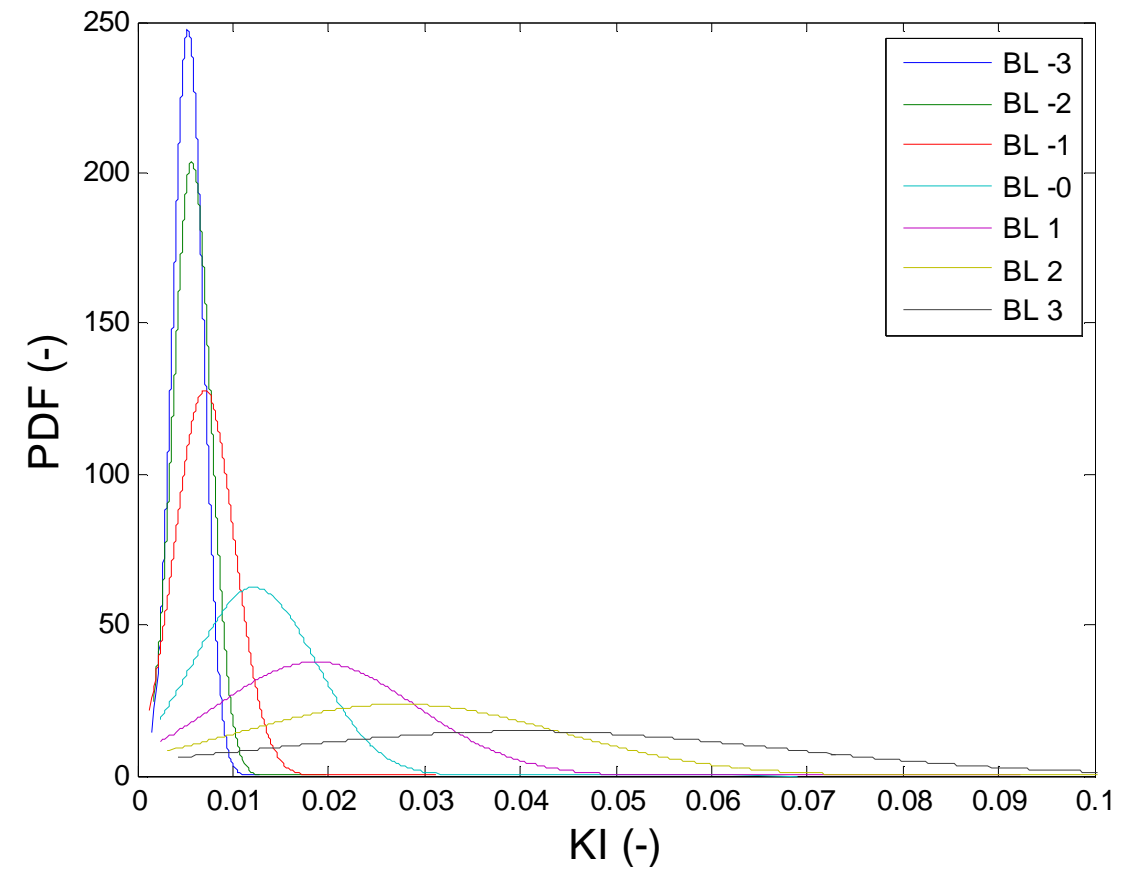

Figure 3-3: Knock intensity data distribution at $1000 \mathrm{rpm}$ at WOT for cylinder 7

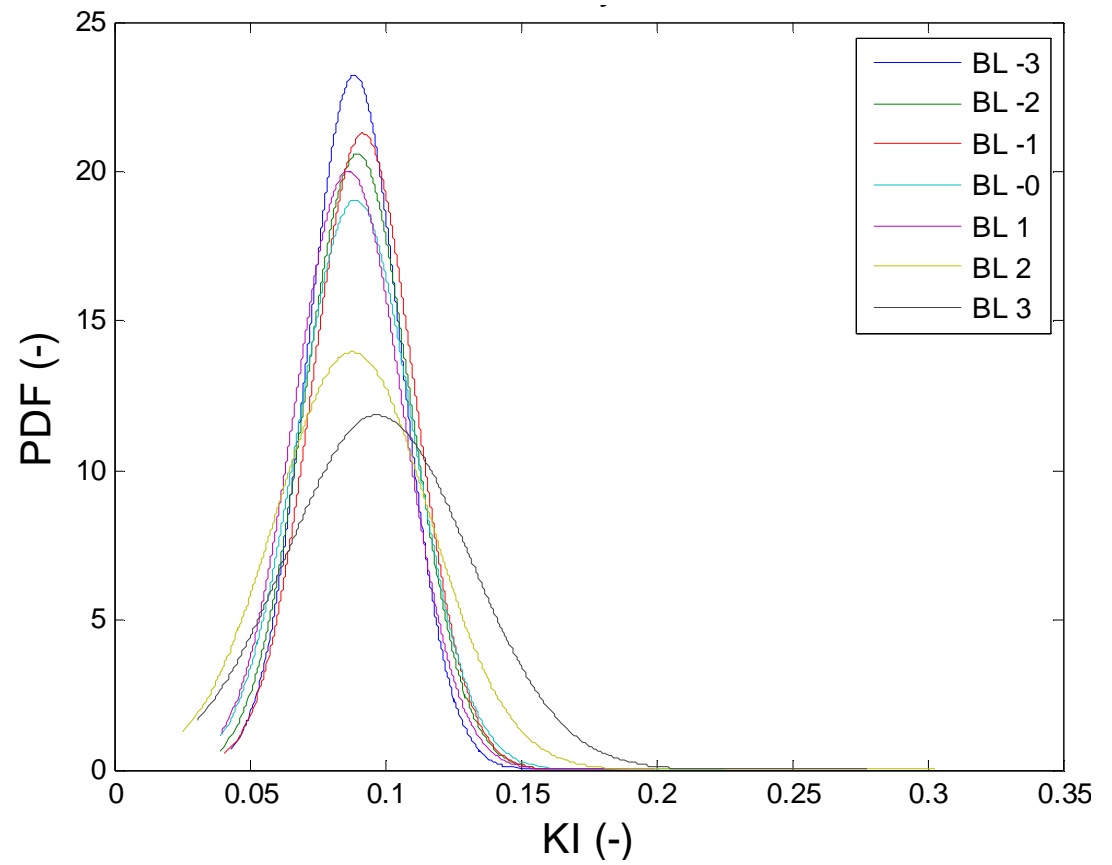

Figure 3-4: Knock intensity data distribution at $5000 \mathrm{rpm}$ at WOT for cylinder 7

Page 21 of 56 


\subsection{KNOCK DETECTION MODULE}

The Knock Detection Module is a SIMULINK block containing various subsystems that implement the SKD method. The Knock Detection Module block is shown in Figure 3-5 and has three inputs "Signal Input", "High Percentile", and "Low Percentile" and one output "Knock Factor". The "Signal Input" is a signal bus containing the current firing cylinder information to be updated and a 1 by 8 array (one for each cylinder) of KI's corresponding to each cylinder's most recent KI value. High and Low percentiles are user defined percentiles used to determine the knock factor per Table 1. The output from the Knock Detection Module is the knock factor defined by equation 9. Subsystem for SKD knock detection module is shown in Figure 3-6, which further has three subsystems "Lognormal Estimates", "Percentile Estimate" and "Knock Factor" these subsystems are SIMULINK implementation of block diagram shown in Figure 3-1.

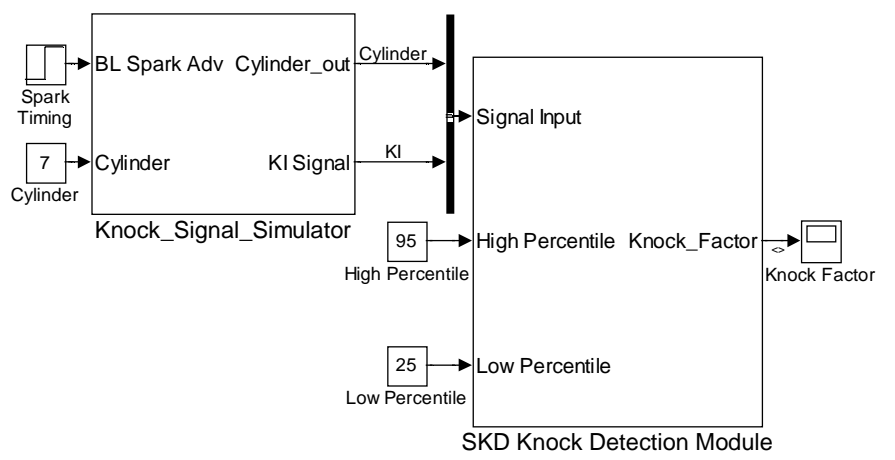

Figure 3-5: Knock detection module.

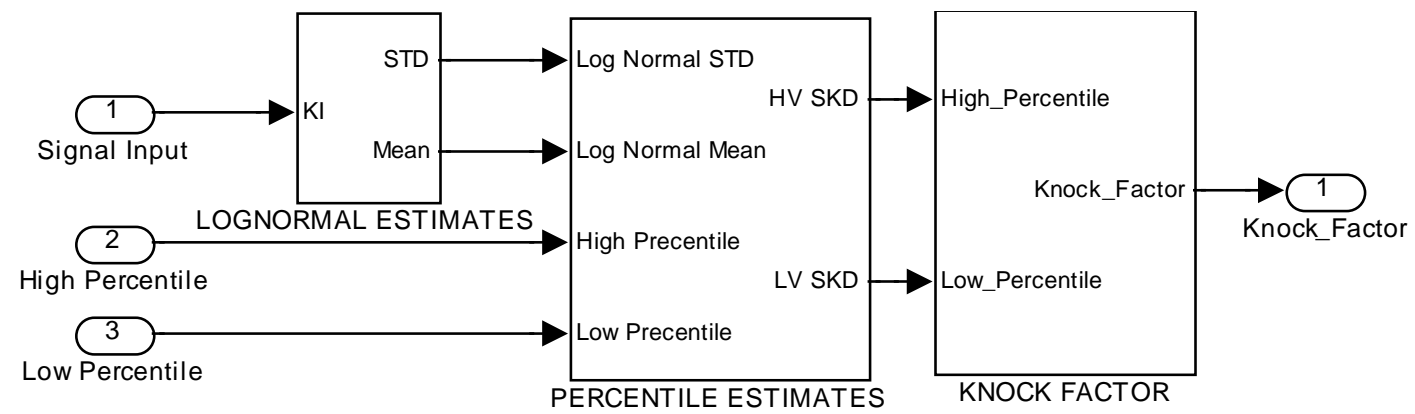

Figure 3-6: SKD Knock detection module subsystem. 


\subsubsection{LOGNORMAL DYNAMIC PARAMETER ESTIMATOR}

Figure 3-7 shows the lognormal parameter estimator subsystem which is based on equations 3,4 and 5. The subsystem estimates lognormal $\widehat{\mu}$ (Mean) and $\widehat{\sigma}$ (STD) by applying a weight function implemented in a digital FIR filter applied to the cycle KI's. The FIR filter coefficients are defined by the variable "b" in the MATLAB workspace which allows the user to adjust the value of each filter weight and number of filter coefficients through the MATLAB command window or through a calibration file. Moreover, the ratio of $n$ and $n-1$ is used to unbias the standard deviation with respect to the number of filter coefficients and is automatically updated when the filter coefficients in array "b" are changed, refer to equation 4 . Here the first value in "b' corresponds to the most recent KI. From previous work by [9], [26] a 30 point FIR filter weighted towards the most recent values was used in this model, which is shown to provide a good trade-off between response and estimation. In fast transients, the filter coefficients can be changed to reduce the estimator lag.

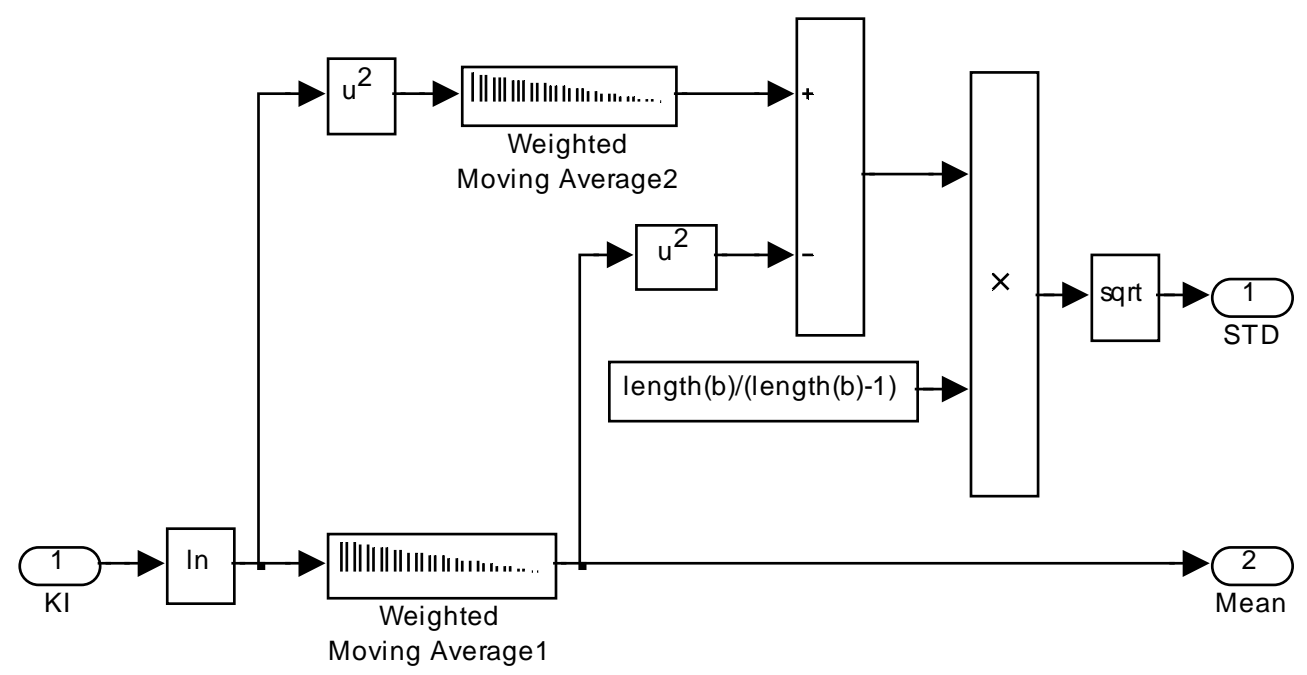

Figure 3-7: Lognormal estimate subsystem.

\subsubsection{PERCENTILE ESTIMATION}

From estimates of the lognormal distribution parameters ( $\widehat{\mu}$ and $\widehat{\sigma})$, the amplitude of knock intensity at different percentiles can be predicted via equation 7 . Knock intensity is estimated at high percentile (HV SKD) to predict the level of combustion knock intensity and at a low percentile (LV SKD) to be used as reference, refer to Table 1. The estimated higher and lower percentiles are HV SKD and LV SKD, respectively. Figure 3-8 contains the SKD knock levels 
subsystem. For each cylinder, the two percentiles HV SKD and LV SKD are predicted from the estimated $\widehat{\mu}$ and $\widehat{\sigma}$ in Figure 3-8 using the function based on equations 7 and 8 . These are user defined and can be changed while the system is in operation. The C21 and C22 blocks are the inverse error function lookup tables described by equation 7 .

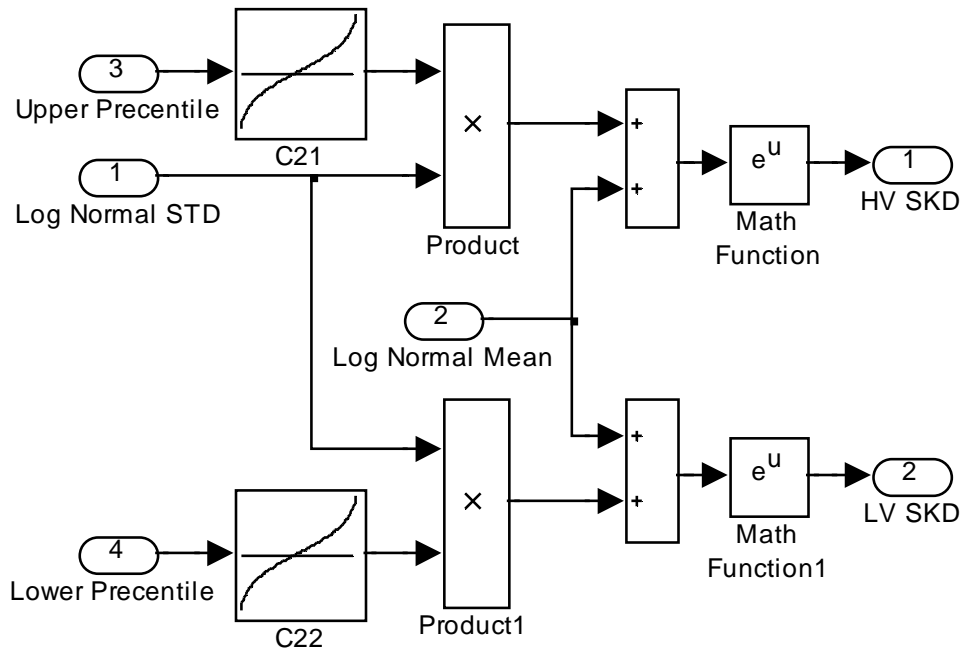

Figure 3-8: Knock level subsystem.

\section{$\underline{3.3 .3 \mathrm{KNOCK} \text { FACTOR }}$}

The knock factor subsystem from Figure 3-6 is shown in Figure 3-9 and is modeled after equation 9 .

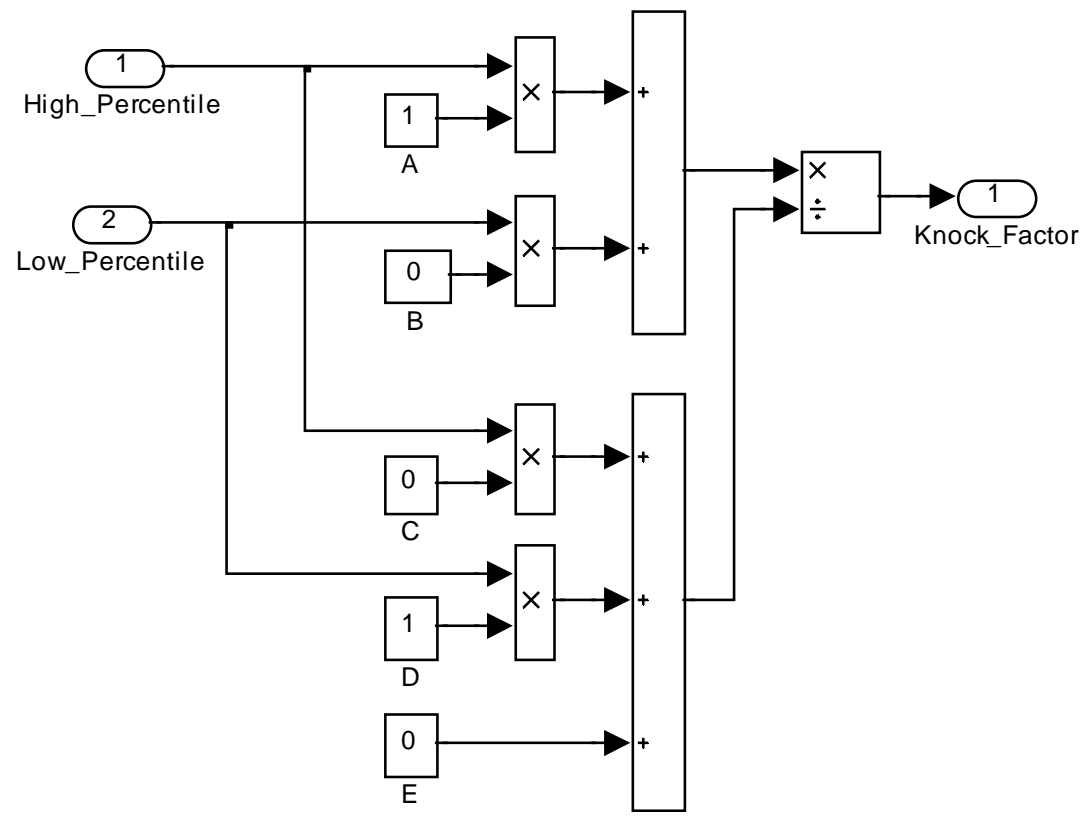

Figure 3-9: Knock factor subsystem.

Page 24 of 56 


\subsubsection{FILTER LENGTH VARIATION DURING TRANSIENT OPERATION}

During transient operating conditions, knock intensity distribution characteristics will change as a result of operational changes in the engine, e.g. speed or load. Under transient conditions it becomes necessary for the lognormal dynamic estimator to respond quickly and accurately to changing operating conditions. In this study, transient operation is simulated by a step change in spark timing $\left(\Delta \mathrm{BL}^{\circ}\right)$, but in real-time, transients could also result from change in speed $(\Delta$ EngineSpeed $(\mathrm{rpm}))$.

So during transient operating conditions knock intensity distribution characteristics may change from a dataset of KI with higher mean that corresponds with particular operating to a dataset of KI with lower mean at a different operating point or vice versa, refer to Figure 3-10. If filter length (current estimator length $\mathrm{N}=30$ ) is kept constant, then during transients some knock intensity values in the filter buffer will belong to the KI dataset of higher value while some knock intensity values will belong to the new KI dataset. The resulting data set of knock intensities (KI) is a combination of KI values of two different knock intensity distributions.

Error in estimation of lognormal standard deviation occurs because of composite distribution formed during transients containing components of two different datasets of knock intensities, which result in a larger combined distribution that covers a range larger than either of the KI dataset distribution. Figure 3-10 graphically represents this explanation. Considering all 30 points in the measurement history skews the distribution estimator.

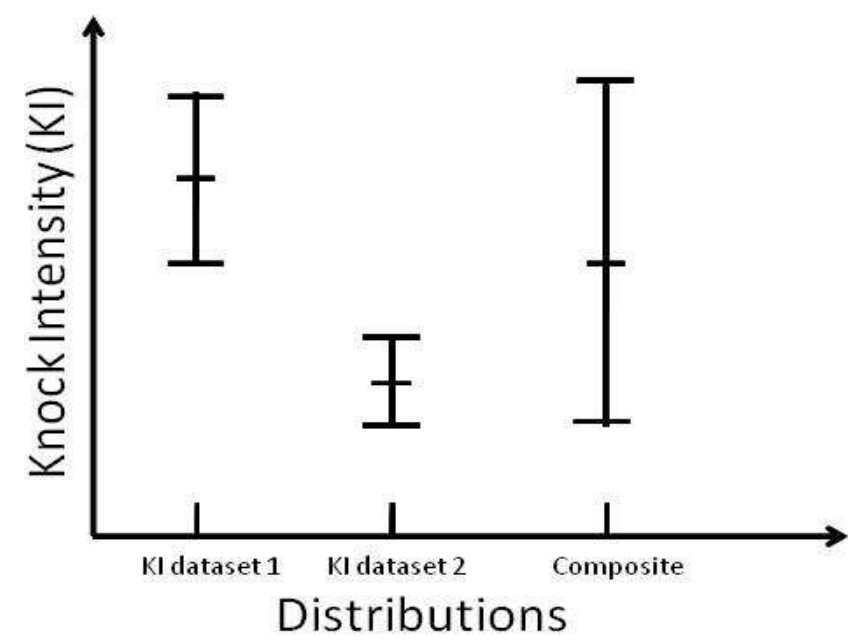

Figure 3-10: Graphical Representation of the Knock Intensity Distributions

Page 25 of 56 
Improvement in transient response is achieved by using SIMULINK 'Weighted Average' block in single-input-multiple-outputs (SIMO) form. Output of the filter can be tapped at different lengths as per user requirement. Figure 3-11 shows schematic of FIR filter in SIMO mode with filter coefficient $b_{j}$, where $\mathrm{j}$ goes from 1 to 30 . When a transient event occurs filter length is dynamically reduced to a smaller size so that at this filter length sufficient transient separation between distributions of knock intensity is obtained. A filter length of $n=5$ provides good transient separation, refer to Section 4.3.2, and is selected when a transient event occurs, then output of SKD is held constant for 5 cycles. After these 5 cycles filter length is gradually increased by one until it reaches the original length of $n=30$.

SIMO - Weighted FIR Filter

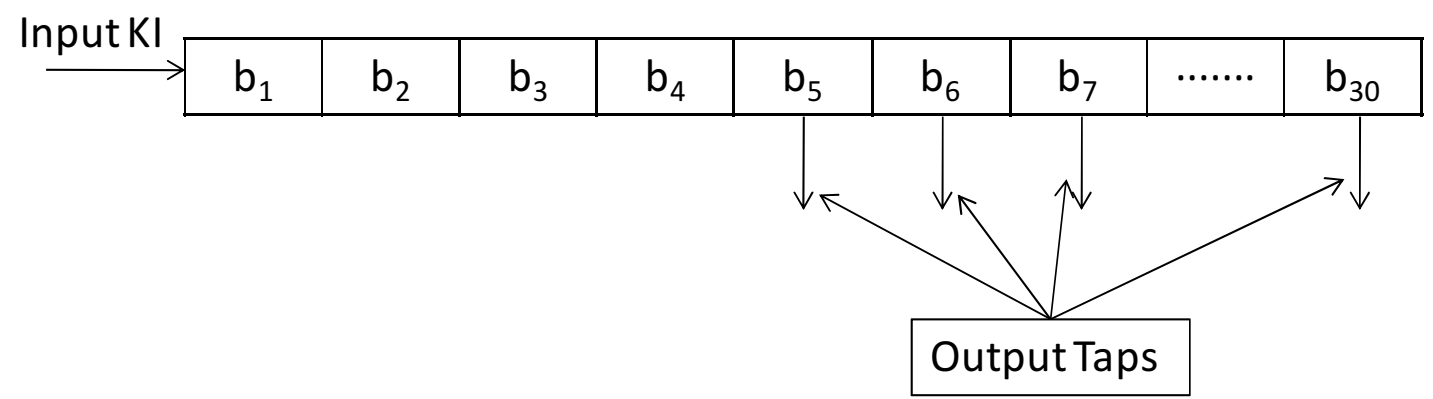

Figure 3-11: Schematic of SIMO FIR Filter

SIMULINK implementation of variable filter length is shown in Figure 3-12. If a strong transient is detected, 'Transient Knock Switch' is enabled which triggers the counter 'Filter Length Selector' to reset the FIR filter and vary the filter length using SIMULINK block - 'Multiport Switch'. 


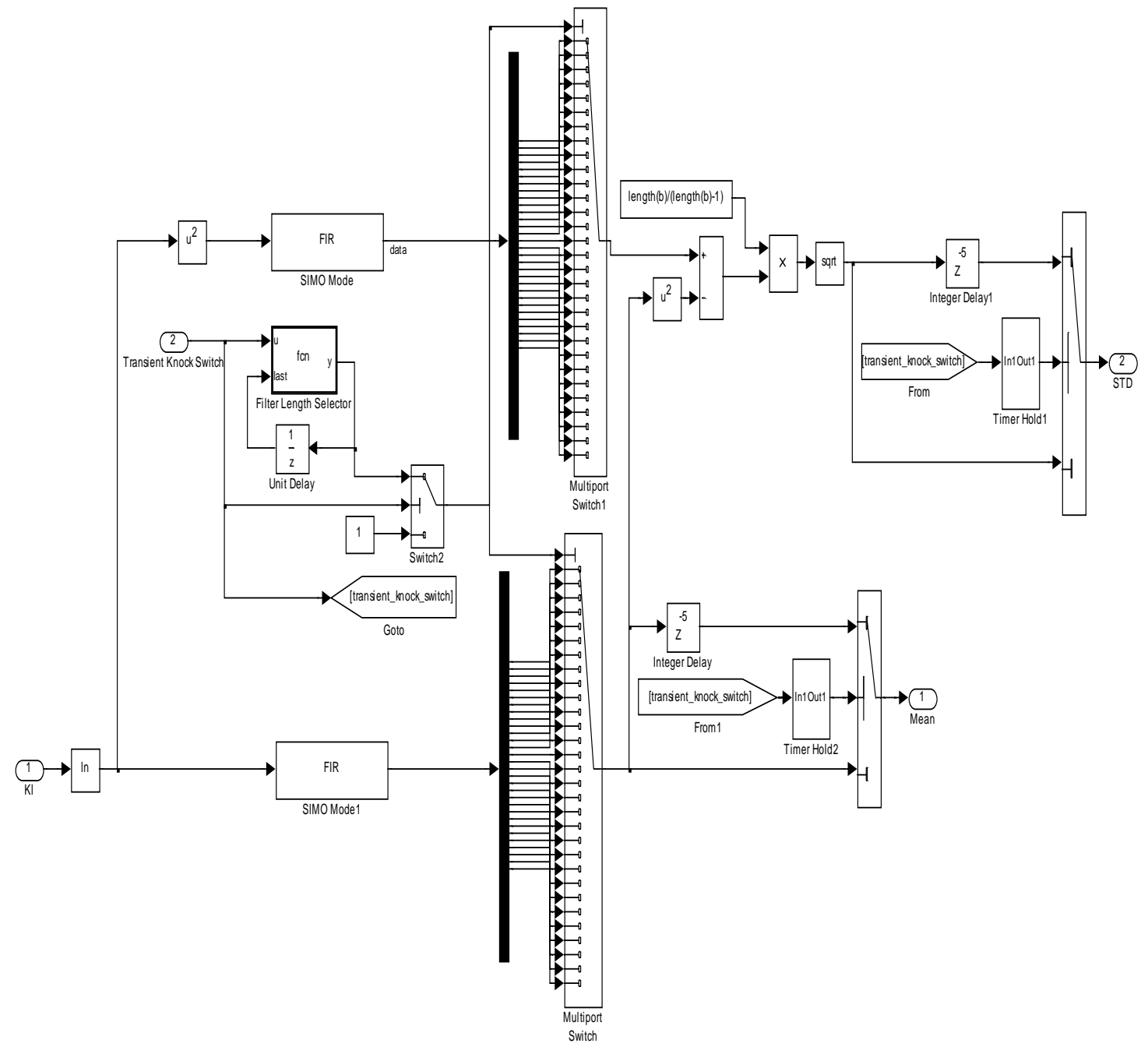

Figure 3-12: Logic for Transient Knock Operation

Page 27 of 56 


\subsection{KNOCK CONTROL MODULE}

Knock control module was developed to demonstrate feedback control using SKD method for knock detection and control. Figure 3-13 shows the simulation model with "Knock Signal Simulator" as the plant model, "SKD Knock Detection Module" estimates knock levels and outputs knock factor as feedback signal "Knock Control Module" which controls knock factor at a calibrated knock factor set-point. Knock Control Module also uses calibrated threshold for gain scheduling.

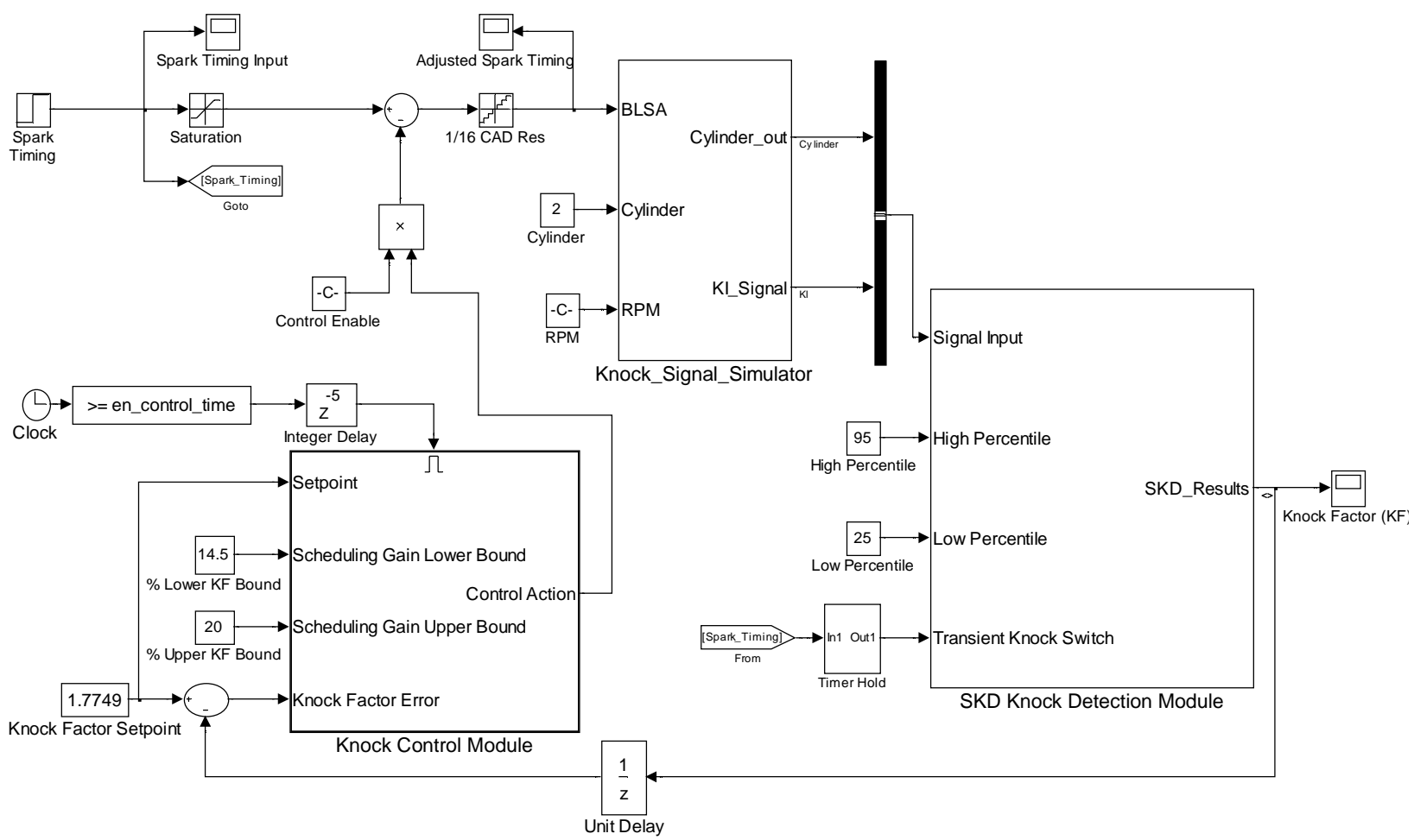

Figure 3-13: Knock Control Simulation Model

The SKD knock controller subsystem is shown in Figure 3-14. The knock controller requires the user to specify a set point for knock metric based on a calibrated value corresponding to the desired level of knock. In addition user can specify integral, derivative and proportional gains. The scheduled gain module decides whether to add the transient gain to the integral control module based on whether the current knock metric error is outside of a user specified percentage range. Gain scheduling is used to meet steady state requirements while maintaining a quick response during transient operations. The integral control module shown in Figure 3-14 accumulates the error to create an integral output.

Page 28 of 56 
Following are design objectives that the controller should meet.

1. Steady state cycle to cycle changes in spark advance cannot exceed $+/-0.5^{\circ}$ of desired borderline knock spark timing.

2. Knock factor values $20 \%$ above or $14.5 \%$ below target set point were considered significantly outside of steady state control thus triggering gain scheduling to operate in transient mode. Once the knock factor reaches steady state conditions, the scheduled gain deactivates allowing the stead state integrator to operate normally.

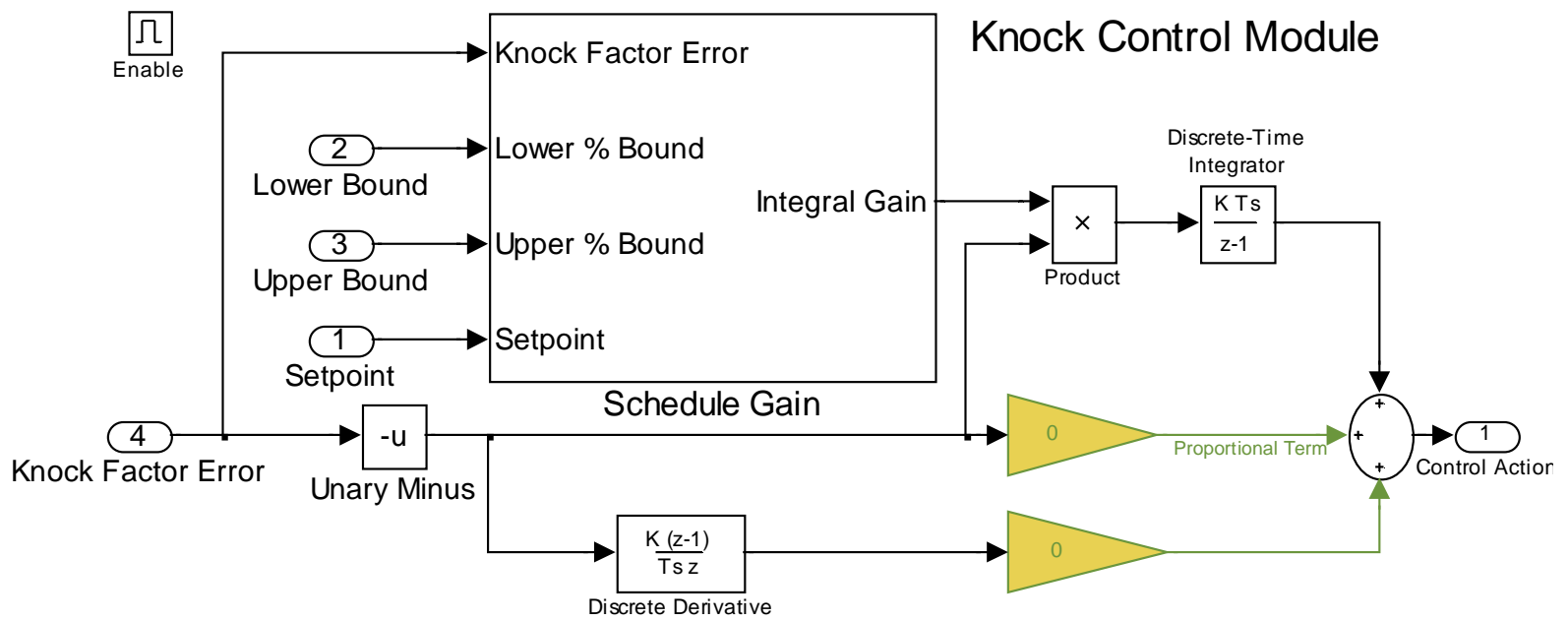

Figure 3-14: Knock Control Module

Selected set-point and limits for gain scheduling are plotted in Figure 3-15, the knock factor variation corresponding to lower and upper bound percentage used for gain scheduling and setpoint corresponding to the mean at each engine speed is shown. Variation in knock factor and target set-point is considerably different for $1000 \mathrm{rpm}$ case because when the data was acquired borderline was determined by the operator, refer Figure 4-3 the actual borderline data corresponds to BL- $2^{\circ}$. Thus determining correct borderline spark timing during calibration at different engine speed is very important. 


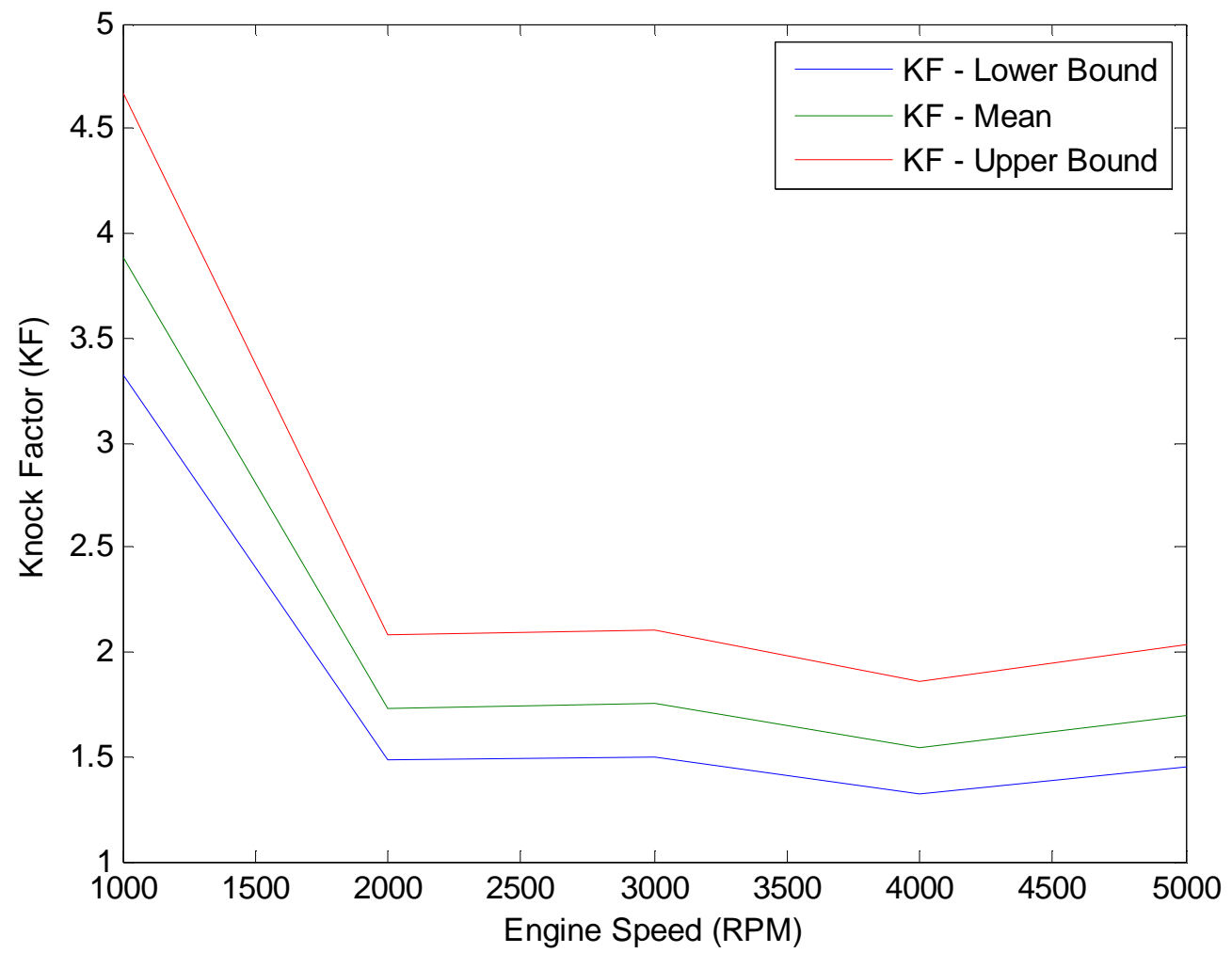

Figure 3-15: Knock Factor variation limits at borderline spark timing used for gain scheduling obtained from cylinder 7 data. 


\section{CHAPTER 4}

\section{RESULTS AND DISCUSSION}

Analysis was performed using V8 engine dataset to develop knock metrics which can be used as feedback signal to control engine knock under a number of operating conditions. As indicated in Section 3.1, experimental data was fed in lookup tables in the KSS, refer Appendix 10.2. This model was simulated for 4000 firing events at various borderline spark advancements (BL- $3^{\circ}$ to $\left.B L+3^{\circ}\right)$ and engine speed. In the development of the knock metric, it is realized that there are two main issues in vibration based knock detection, signal referencing and knock sensitivity, which much be accounted for. The following discusses these issues and how they are accounted for in the development of a SKD knock metric.

\subsection{SIGNAL REFERENCING}

Need for referencing of the knock intensity $(K I)$ amplitude of the signal is two-fold (1) to compensate for the variable sensitivity of sensor and (2) to account for background signal (noise) that changes with engine speed, load and cam phasing for engines with variable cam timing (VCT). In one common method, the $K I$ is normalized by a reference value which is measured during a separate crank-angle window preceding the knock window [7]. This method requires the calibration of a second window for each speed/load point and finding a window without excessive noise from valve closure which becomes more difficult for high cylinder count engines. Additionally, in the case of VCT engines, the position now must be calibrated in conjunction with the engine calibration for cam phasing. A second method uses the $K I$ signal from the same window and events. Special logic is required to determine on a firing basis whether to include the signal in the reference or not $[7,8]$. This requires calibration of the separation logic and often separation of events is not exact such that the reference method includes light combustion knock or combustion rumble. Similar processes for referencing/normalization are required for ionization based methods [9]. 
This issue is addressed directly by the SKD method by continually referencing estimated high percentile of KI with estimated low percentile KI estimated and no special logic is required. In this work a $25^{\text {th }}$ percentile for the estimated distribution is used for referencing. The referencing/normalization can be performed in a number of methods outline in Table 1.

\subsection{KNOCK SENSITIVITY}

The knock metric should show good sensitivity to knock and separation from background levels under all operating conditions. In a study to compare different metrics for knock detection [2], it was shown that the background noise levels can be minimized by proper selection of band-pass filter frequencies and crank-angle window in vibration-based methods for knock detection, but it is greatly affected by changes in engine operating conditions.

From section 3, the first SKD $K F$, "KI95/KI25" was found to have good separation between knocking and no knock spark advances. To compare the SKD method to current knock detection strategies, a knock factor $K F_{\text {Classsic }}$ of the form shown in Equation 12 was used. $K F_{\text {Classic }}$ is the ratio of the knock intensity divided by a reference, which in this case is the mean of no knock intensities $(K R)$. This metric is representative of the current knock detection methods because it uses individual accelerometer intensity in a single window approach from a cylinder to determine whether knock is present on an individual cycle basis. For SKD the knock factor $K F_{S K D}$ is used,

$$
K F_{S K D}=\frac{K I 95}{K I 25}
$$

and for a knock factor representative of classical single window methods the following is used

$$
K F_{\text {Classic }}=\frac{K I}{K R}
$$

where,

KI25 - SKD lognormal estimated $25^{\text {th }}$ percentile,

KI95 - SKD lognormal estimated $95^{\text {th }}$ percentile,

KI - Instantaneous knock intensity for the current cycle,

Page 32 of 56 
$K R$ - Running average of knock intensity of past 30 events eliminating intensities greater than $+1.96 \cdot \widehat{\sigma}$.

The cycle-to-cycle value of each knock factor is ideally expected to indicate the propensity of the engine to knock if conditions (e.g., spark advance) were not changed. Figure 4-3 shows the SKD and Classical knock factors as a function of Borderline Spark Advance (BLSA) from BLSA-3 ${ }^{\circ}$ to $\mathrm{BLSA}+3^{\circ}$ as determined by the test operator.

Figure 4-1 and Figure 4-2 show the distribution of the SKD and classic knock metrics at seven different borderline spark timings $\left(\mathrm{BLSA}-3^{\circ}\right.$ to $\left.\mathrm{BLSA}+3^{\circ}\right)$. As shown, the SKD knock factor shows improved separation and reduced variability as the spark is advanced above borderline than the classical knock factor. Figure 4-3 shows a comparison of $K F_{S K D}$ and $K F_{\text {Classic }}$ for cylinder 7 at different engine speeds and six borderline spark timings; it can be observed that $K F_{S K D}$ shows a better separation and sensitivity to knock than $K F_{\text {Classic }}$. A further analysis is done to provide a quantitative measure of separation at varying knock levels.

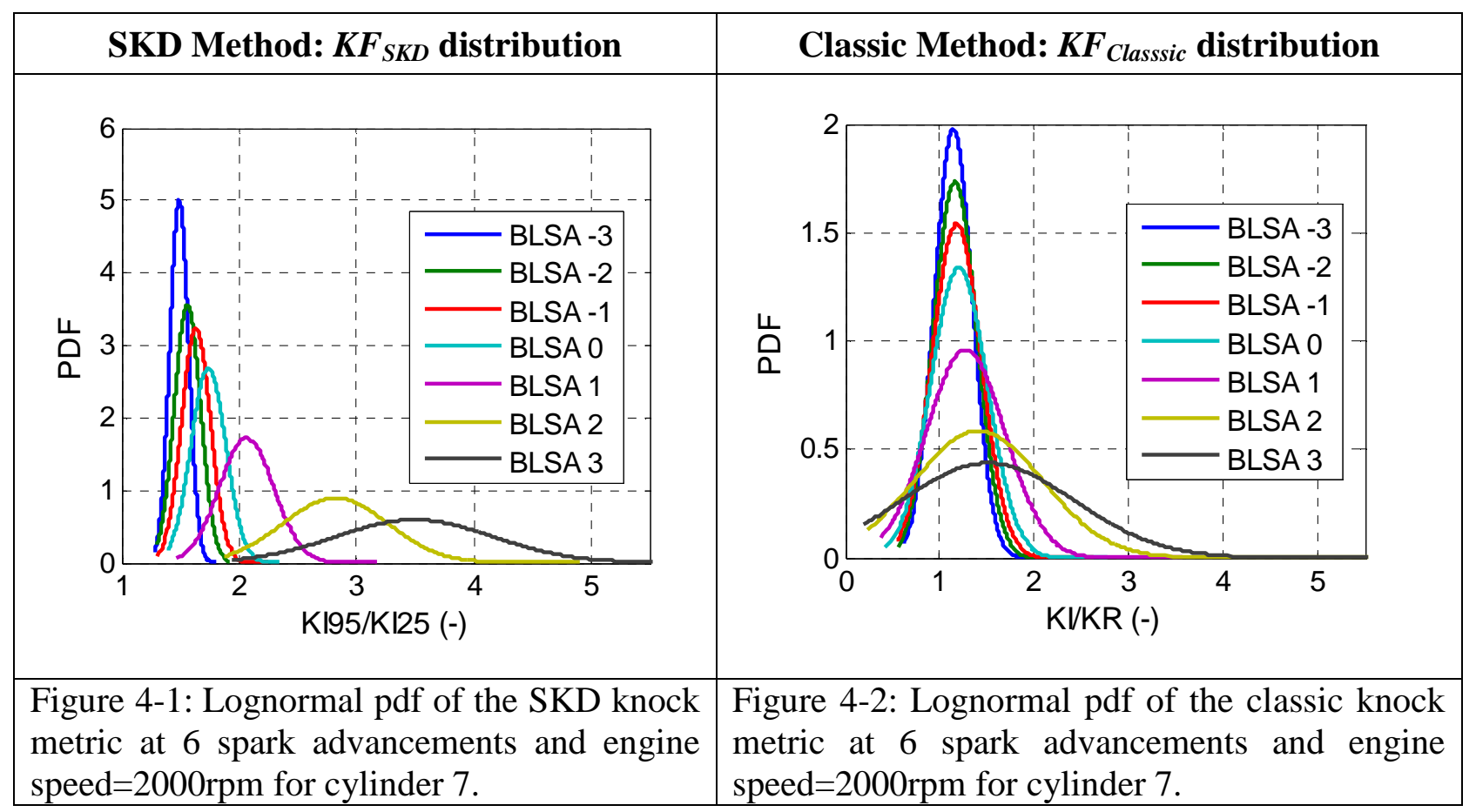




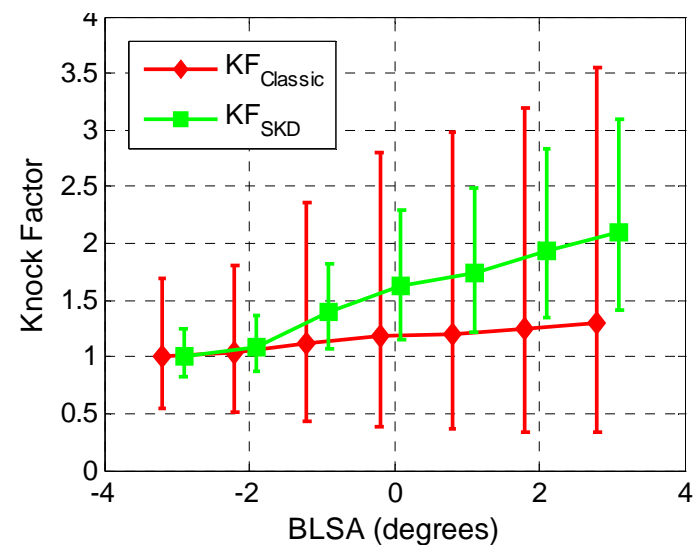

(a)

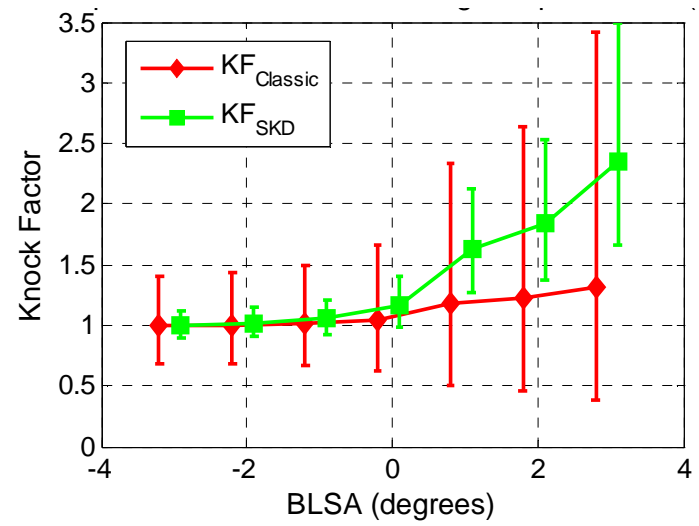

(c)

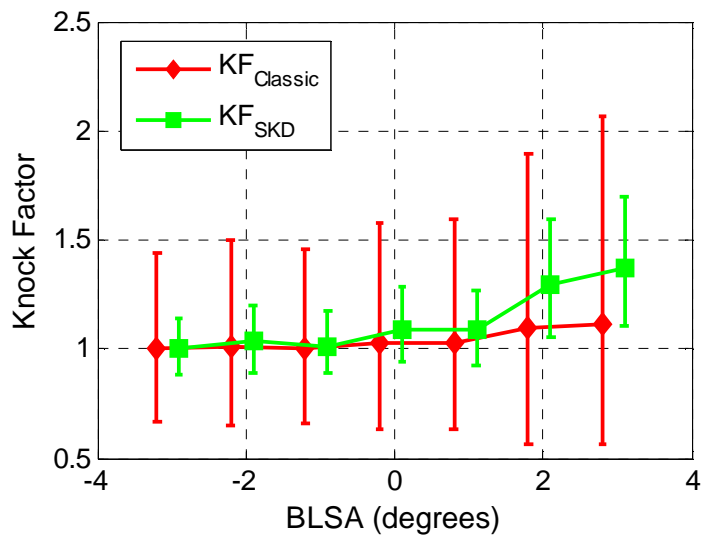

(e)

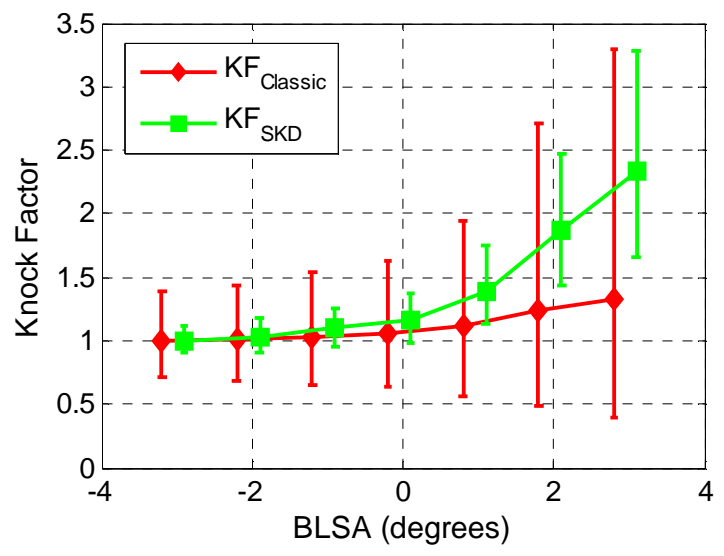

(b)

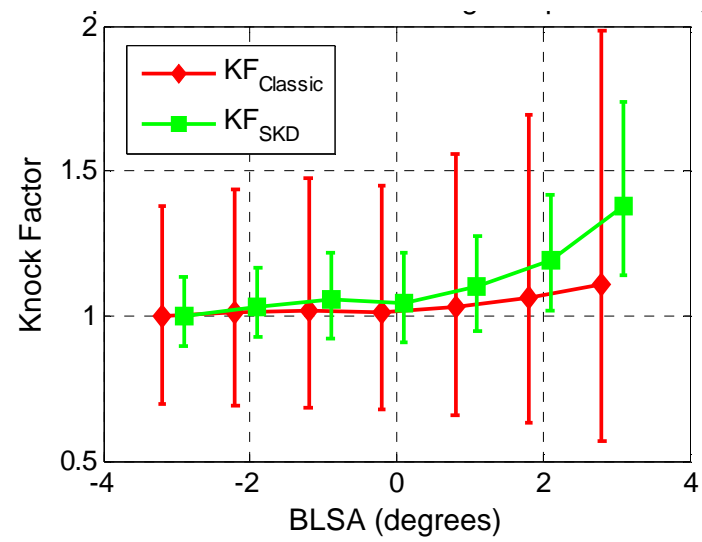

(d)

Figure 4-3: Knock Factor comparison for cylinder 7 for BL-3 ${ }^{\circ}$ to $B L+3^{\circ}$ : (a) Engine Speed $=$ 1000rpm, (b) Engine Speed=2000rpm, (c) Engine Speed=3000rpm, (d) Engine Speed=5000rpm and (e) Engine Speed=6000rpm. 


\subsection{KNOCK METRIC SEPARATION}

Most knock control strategies attempt to operate as close as possible to borderline knock without significant overlap with knocking conditions. The ability of the knock feedback metrics to accurately detect this borderline condition without significant false-positive (Type 1 error [28]) overlap will be critical to the design of effective knock controllers. A separation factor was created to quantify the overlap between the knock factor values at different spark timings. The knock metric values associated with the borderline knock condition $\left(\mathrm{BL} 0^{\circ}\right)$ were used as reference to measure the overlap between the borderline and knocking conditions.

\subsubsection{Separation Factor}

To compare the detection capabilities of each knock factor, the separation factor is used to measure the separation between no knock and knocking values of each knock factor. A good knock metric should have the capability to distinguish between knocking and no knocking conditions as well as discern between different intensity levels of engine knock. To meet these guidelines, the knock metric should have a unique mean value at different knock intensity levels that are significantly different given statistical measurements of the confidence interval on the mean value. The separation factor $(S F)$ given in equation 13 is a normalized measure of the difference between the average knock factor at conditions being tested $\left(\mu_{K F}\right)$ and a reference knock metric value characteristic of no engine knock $\left(\mu_{\text {ref }}\right)$. The metric is obtained by normalizing the distribution mean of knock factor values by the sum of standard deviations of the knock factor at the test condition. Larger separation factors indicate larger differences between knocking and no knocking conditions and a reduction in the overlap between knock metric values at different levels of engine knock.

$$
S F=\frac{\mu_{K F}-\mu_{r e f}}{\sigma_{K F}+\sigma_{\text {ref }}}
$$

Equation 13

Figure 4-4 and Figure 4-5 show the change in the separation factor as a function of borderline spark advance for the two knock metrics. The separation factor was measured at different levels of spark advance with respect to borderline for cylinder 7. The reference mean and standard deviation used in the separation was taken from data produced from the engine operating at a spark timing of $\mathrm{BL}^{\circ}$. At each spark advance, the mean value and standard deviation of each knock metric was computed using 4000 simulation engine cycles. As shown in the figure, the Page 35 of 56 
SKD metric has a larger separation factor by a factor of 10 times the "Classic" knock factors separation. From these plots, the advantages of the SKD method over the "Classic" knock detection methods can clearly be seen as a larger separation factor indicates a potentially significant reduction in number of false positive knock detections.

\begin{tabular}{|c|c|c|}
\hline \multicolumn{2}{|c|}{ SKD Method } & \multicolumn{2}{c|}{ Classic Method } \\
\hline 2.5 & & \\
\hline
\end{tabular}

\subsubsection{Transient Separation}

To determine the transient response when engine transitions from non-knocking to knocking state or for when a speed/load transient occurs such as a tip-in, the estimator should be able to respond within a 30 cycles such that the control system can quickly adjust to the new borderline spark advance. To quantify this with the lognormal estimator, simulation of transition from a noknock condition to a knock condition was done to characterize the response by the separation of the estimated KI95 value (equation 14) and number of firing events needed to reach $80 \%$ of the new knocking KI95. This simulation was done with different weighting and data (buffer) lengths [9]. Specifically the transient separation factor is given by

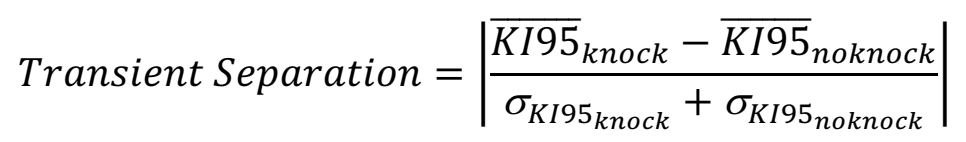


Transient response time T80 is the number of events needed to reach $80 \%$ of mean of estimated KI95 in knocking condition from mean of estimated KI95 under the non-knocking condition. The Figure 4-6 shows T80 for weighted filter lengths of 5 to 100 with the filter weights given in equation 5. As seen in the Figure 4-6 as the FIR filter length increases the transient separation factor increases, but at the cost of a slower (longer number of events) response to T80. A filter length of 30 provides transient separation equal to 3 with a response time of 16 events. This is provide good separation but probably is to slow for transient operations. At the minimum FIR length examined of 5 , we have a response of 4 cycles and a separation of just above 1 . It is proposed that in the FIR length could be dynamically adjusted, such that when a transient occurs the filter length is reset to a small value (e.g. 5) and is increased as the number of cycles at that condition increase. There is still an issue of how to control knock on during the first few cycles into a transient, but a number of existing feed-forward and purely calibrated methods could be applied until the estimator develops a valid knock factor.

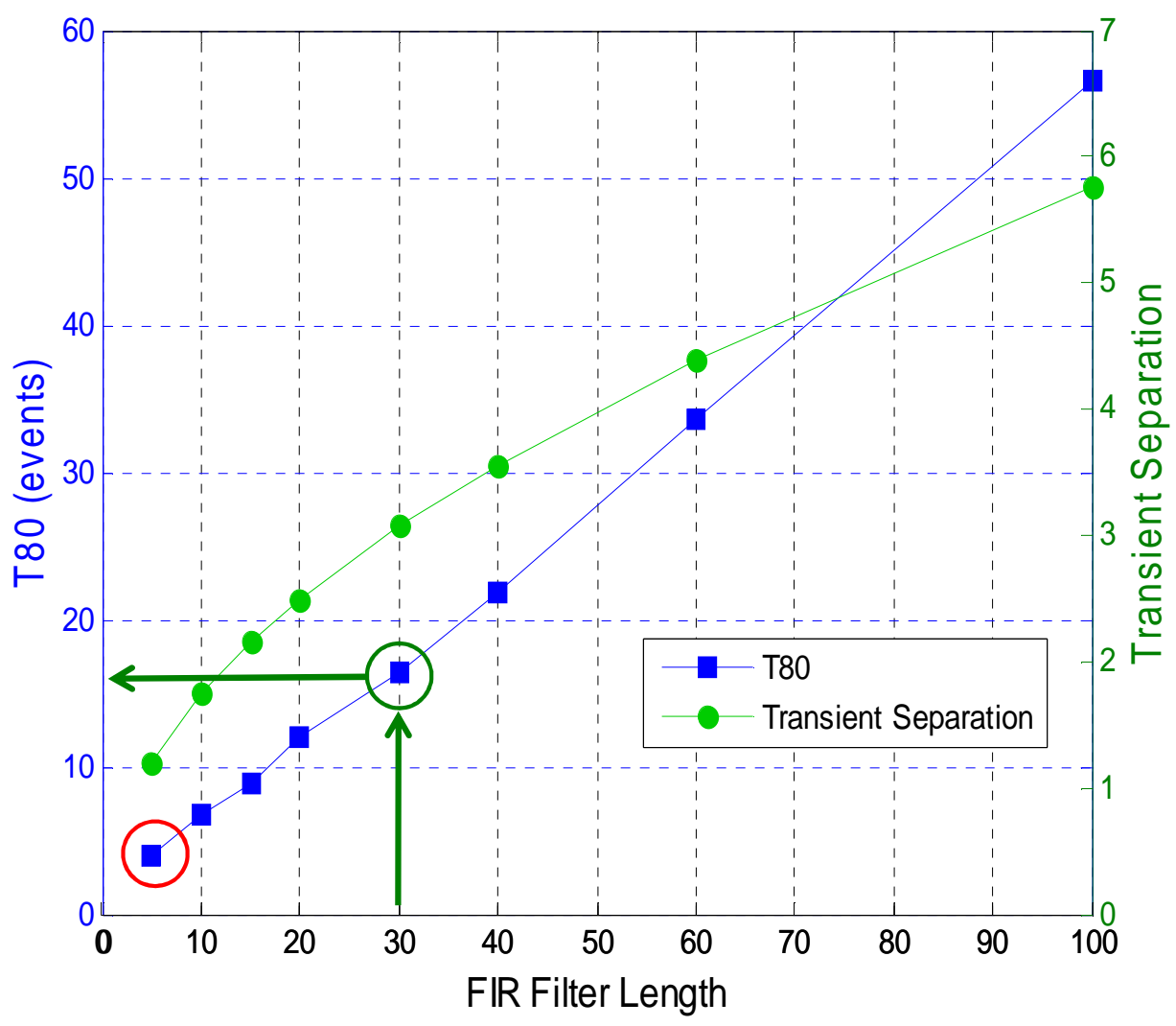

Figure 4-6: Transient response of different FIR filter lengths. 


\subsection{SKD TRANSIENT RESPONSE SIMULATION}

Transient response characteristic of the SKD estimator was evaluated for variable and constant FIR filter lengths. Step transition in knock levels from BL0 to BL10 at 2000 r.p.m at WOT was simulated using Ford V8 cylinder 7 data. Step transitions were simulated 400 times and averaged characteristics of knock factor ( $\mathrm{KF}_{\mathrm{SKD}}$ ), estimated lognormal mean $\widehat{\mu}$ and estimated lognormal standard deviation $\widehat{\sigma}$ were obtained for both variable and constant filter lengths.

For constant filter length Figure 3-10 shows the effect of composite distribution discussed in section 3.3.4 due to delay in updating KI values during transient operation. This leads to increase in estimated standard deviation, see Figure 4-7 and Figure 4-8. As a result there is a significant overshoot in estimated $\mathrm{KF}_{\text {SKD }}$ values during transients. From Figure 4-9 and Figure 4-10 we see that estimated mean $\widehat{\mu}$ is well behaved, but the estimated standard deviation $\widehat{\sigma}$ is incorrect which in turn caused the $\mathrm{KF}_{\mathrm{SKD}}$ values to be incorrect. This effect is observed during transition from low to high knock levels and vice versa.

With variable filter length transient response is improved as filter length reduces and old KI values are no longer considered in the estimation. It should be kept in mind that a trade off needs to be achieved between response time and accuracy of estimated parameters. Lower filter lengths also cause larger variations in estimated parameters.

Transient average knock factor $\mathrm{KF}_{\mathrm{SKD}}$ for 400 step transitions from $\mathrm{BL} 0^{\circ}$ to $\mathrm{BL}+10^{\circ}$, upper and lower bounds of $\mathrm{KF}_{\mathrm{SKD}}$ are shown in Figure 4-11 and Figure 4-12. Upper and lower bounds represent $95^{\text {th }}$ and $25^{\text {th }}$ percentile of the data set of $\mathrm{KF}_{\mathrm{SKD}}$ formed by 400 step transition. 

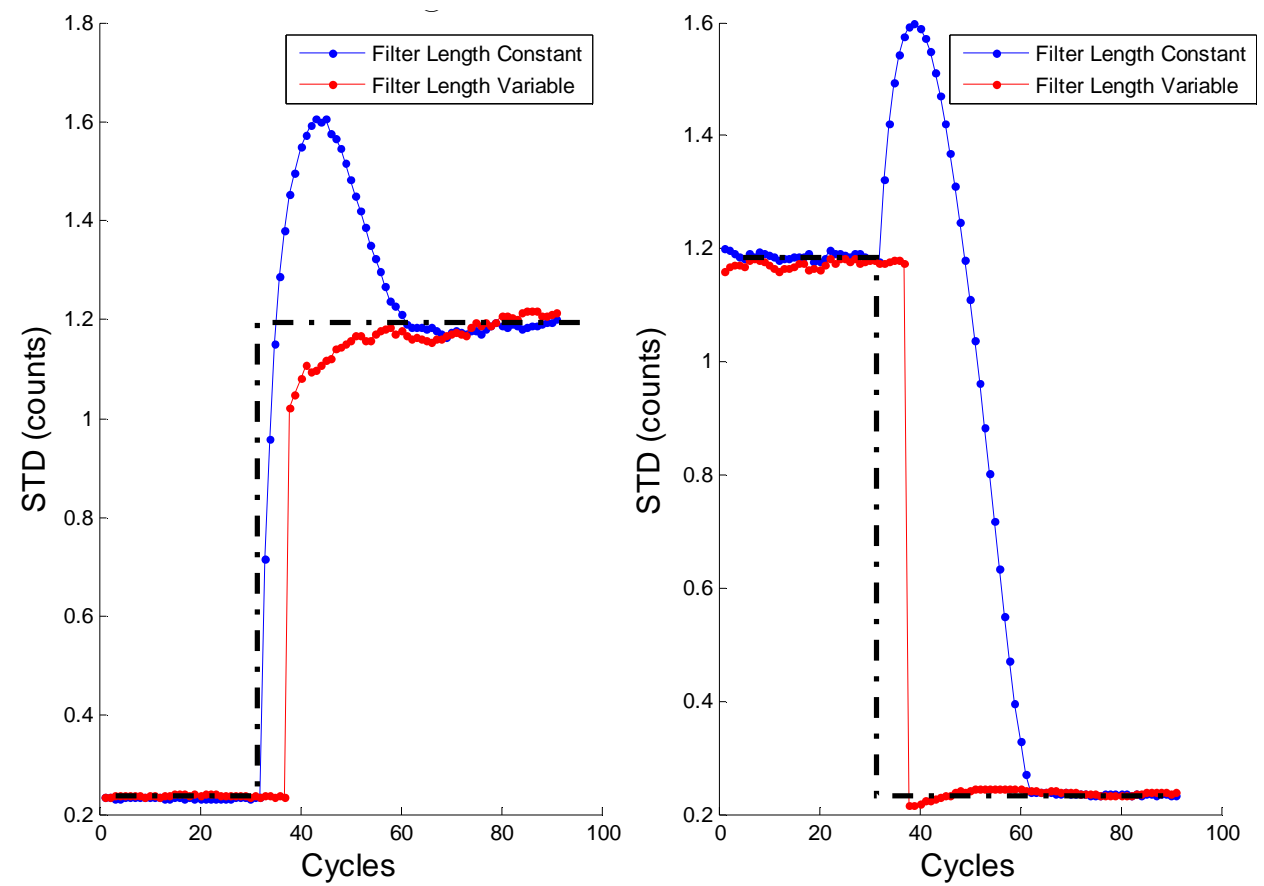

Figure 4-7: Average of estimated lognormal $\widehat{\sigma}$
during transient knock operation from low

Figure 4-8: Average of estimated lognormal $\widehat{\sigma}$ during transient knock operation from low knock level $\mathrm{BL}^{\circ}$ to high knock level BL $+10^{\circ}$ knock level $\mathrm{BL}^{\circ}$ to high knock level $\mathrm{BL}+10^{\circ}$
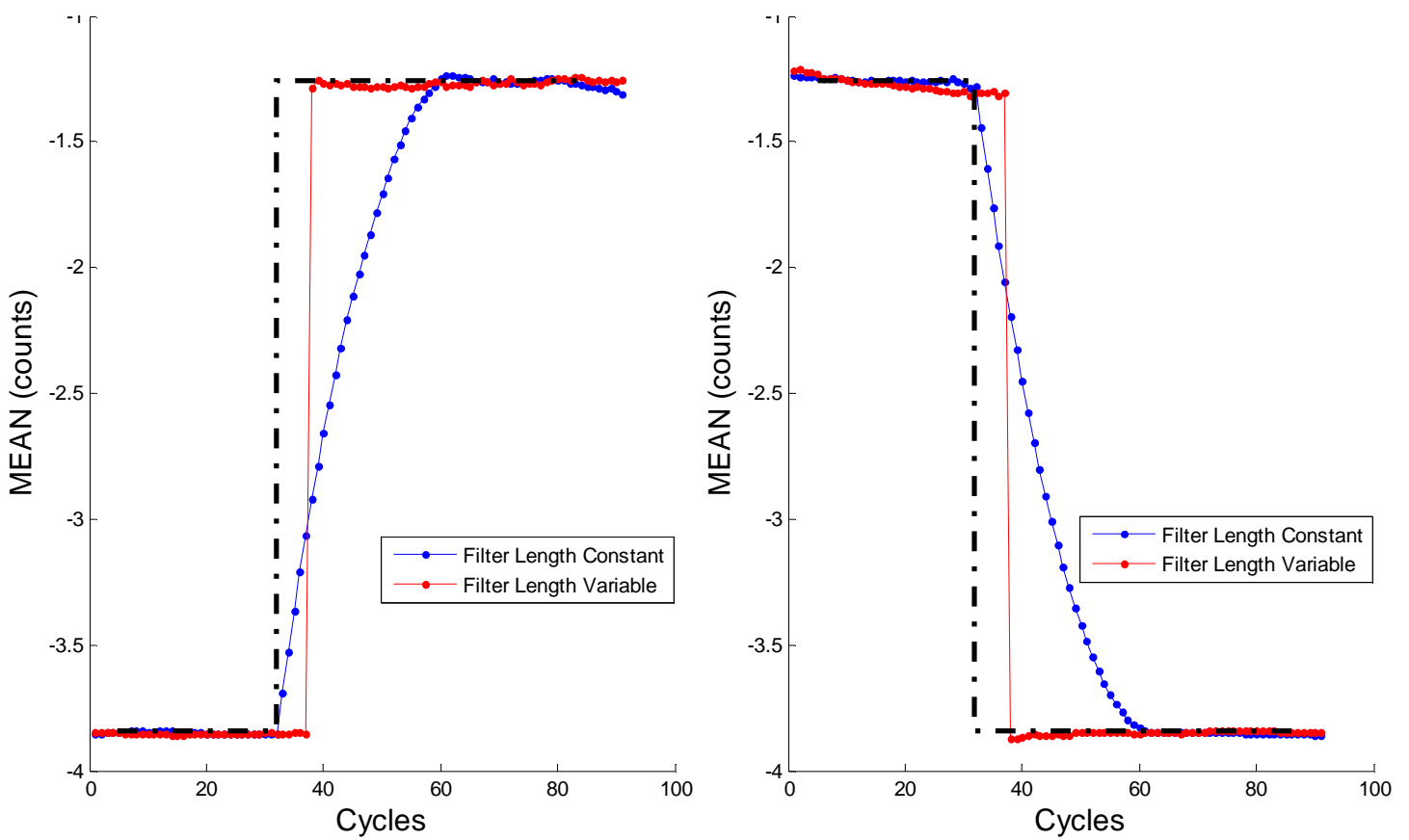

Figure 4-9: Average of estimated lognormal $\widehat{\mu}$ during transient knock operation from low knock level $\mathrm{BL}^{\circ}$ to high knock level $\mathrm{BL}+10^{\circ}$
Figure 4-10: Average of estimated lognormal $\widehat{\mu}$ during transient knock operation from low knock level $\mathrm{BL}^{\circ}$ to high knock level $\mathrm{BL}+10^{\circ}$ 


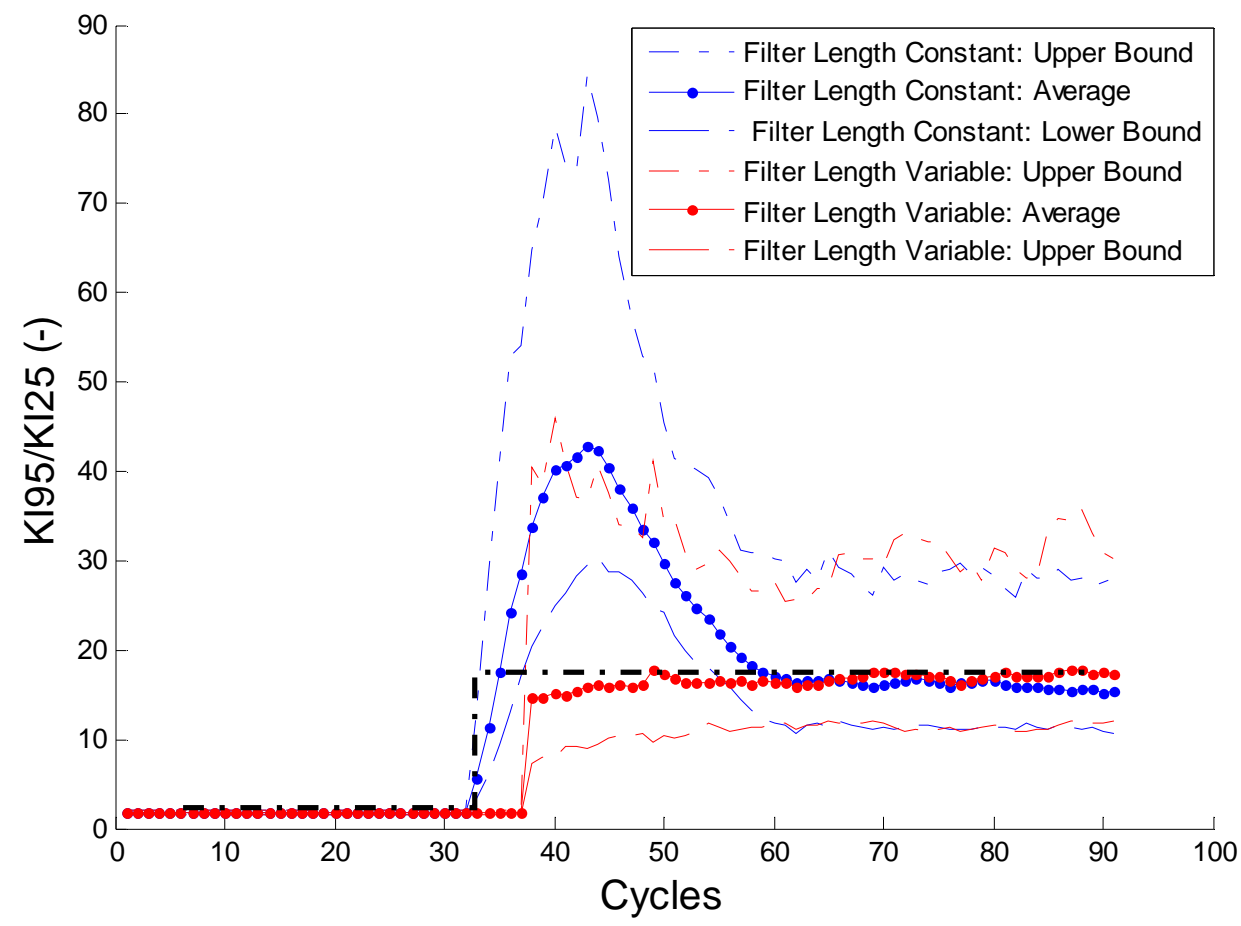

Figure 4-11: Knock Factor for knock transition from $B L 0^{\circ}$ to $B L+10^{\circ}$

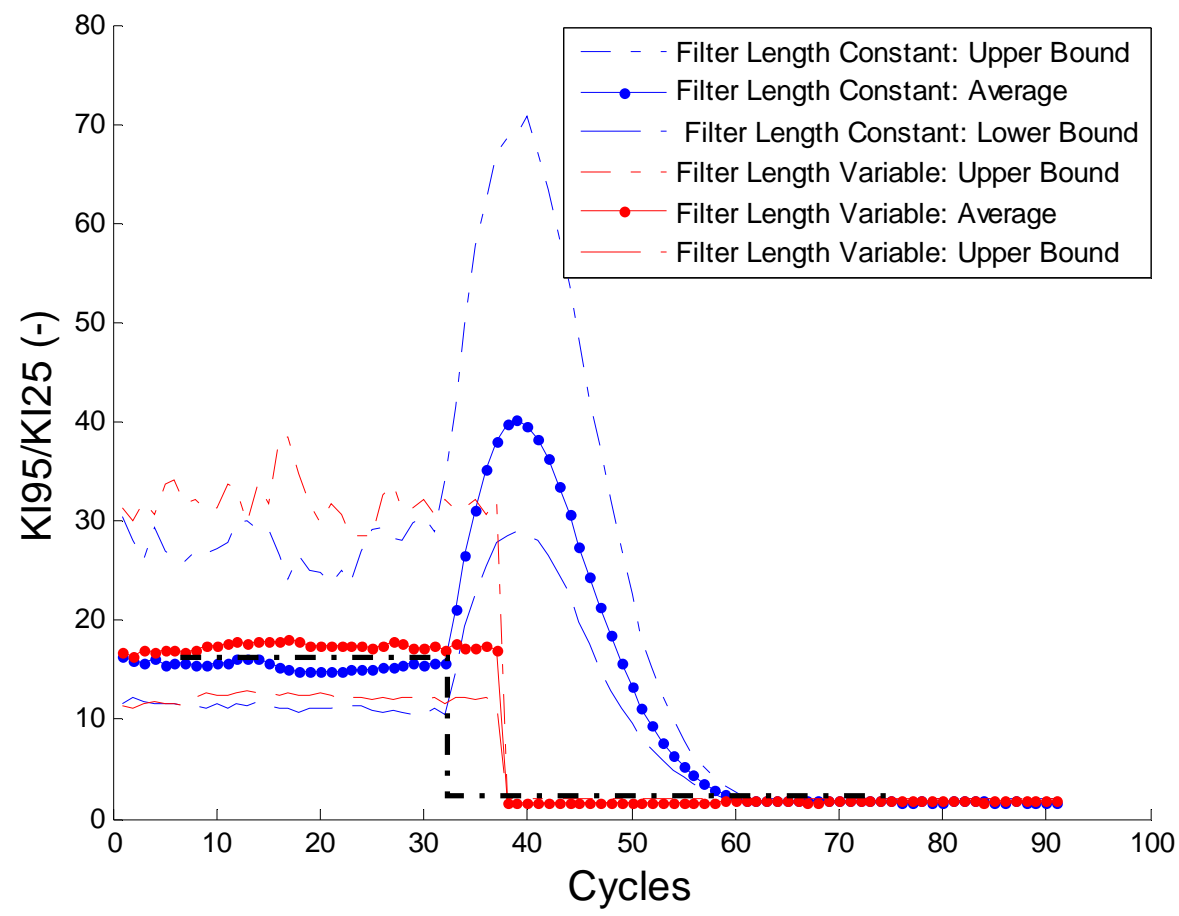

Figure 4-12: Knock Factor for knock transition from $\mathrm{BL}+10^{\circ}$ to $\mathrm{BL} 0^{\circ}$ 


\section{$\underline{4.5 \text { KNOCK CONTROLLER SIMULATION }}$}

Integral control was used to demonstrate knock control using SKD method proposed in this report (refer Section 3.4 for implementation details of the controller). The integral gain controller was use because of steady state variation in control variable $\left(\mathrm{KF}_{\mathrm{SKD}}\right)$. Due to these steady state variations in control variable itself proportional and derivative gains cause oscillations in control action [26]. Thus proportional and derivative gains were set to zero.

\subsubsection{Borderline Knock Level - Set-point}

The borderline knock level is the set-point value for the control system. It was found using the knock simulator by setting the spark timing to a value of zero which corresponded to the borderline knock condition. The mean value of knock factor $\mathrm{KF}_{\mathrm{SKD}}$ at the borderline spark timing was used as the set-point for the controller. For $\mathrm{BL} 0^{\circ}$, mean value of $\mathrm{KF}_{\mathrm{SKD}}=1.8$ was chosen as the set-point corresponding to the borderline knock metric value. Figure 4-13 shows the simulated knock factor at the BL0 condition over 4000 engine cycles.

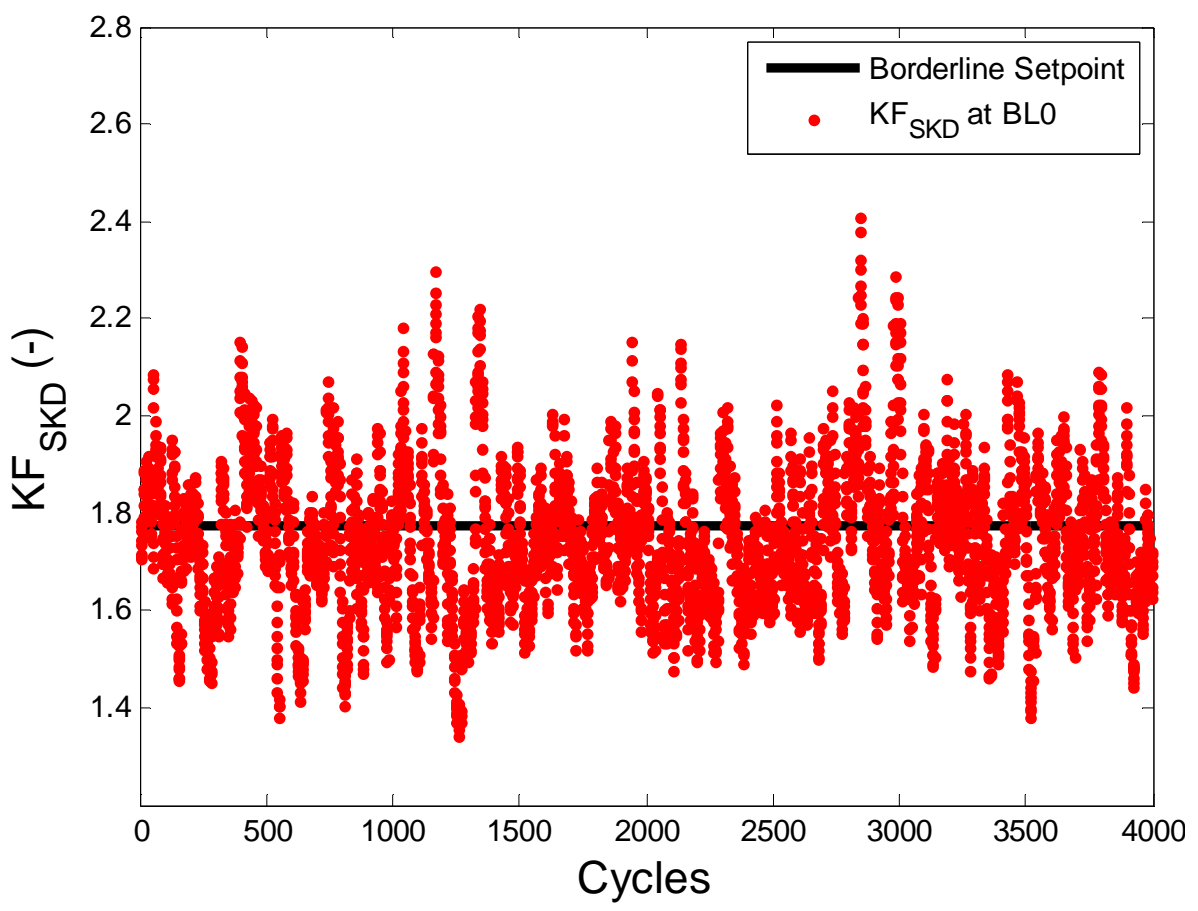

Figure 4-13: Knock Factor variation at borderline spark advance, 2000 rpm and WOT for cylinder 7 


\subsubsection{Controller Response}

Controller must have a good steady state response with respect to spark advance but must also be capable of responding quickly to sudden changes in the knock intensity by retarding spark timing which may occur due to changes in the fuel or engine operating conditions. To decrease the response time, the knock control has scheduled 'transient' and 'steady state' integral gains. Transient gain is activated when knock factor value is outside steady state range. It should be note that controller is used as an example to demonstrate knock control, so the gain values were obtained with little effort to tune these for optimal performance. Further calibration effort is needed to optimize the performance of knock controller.

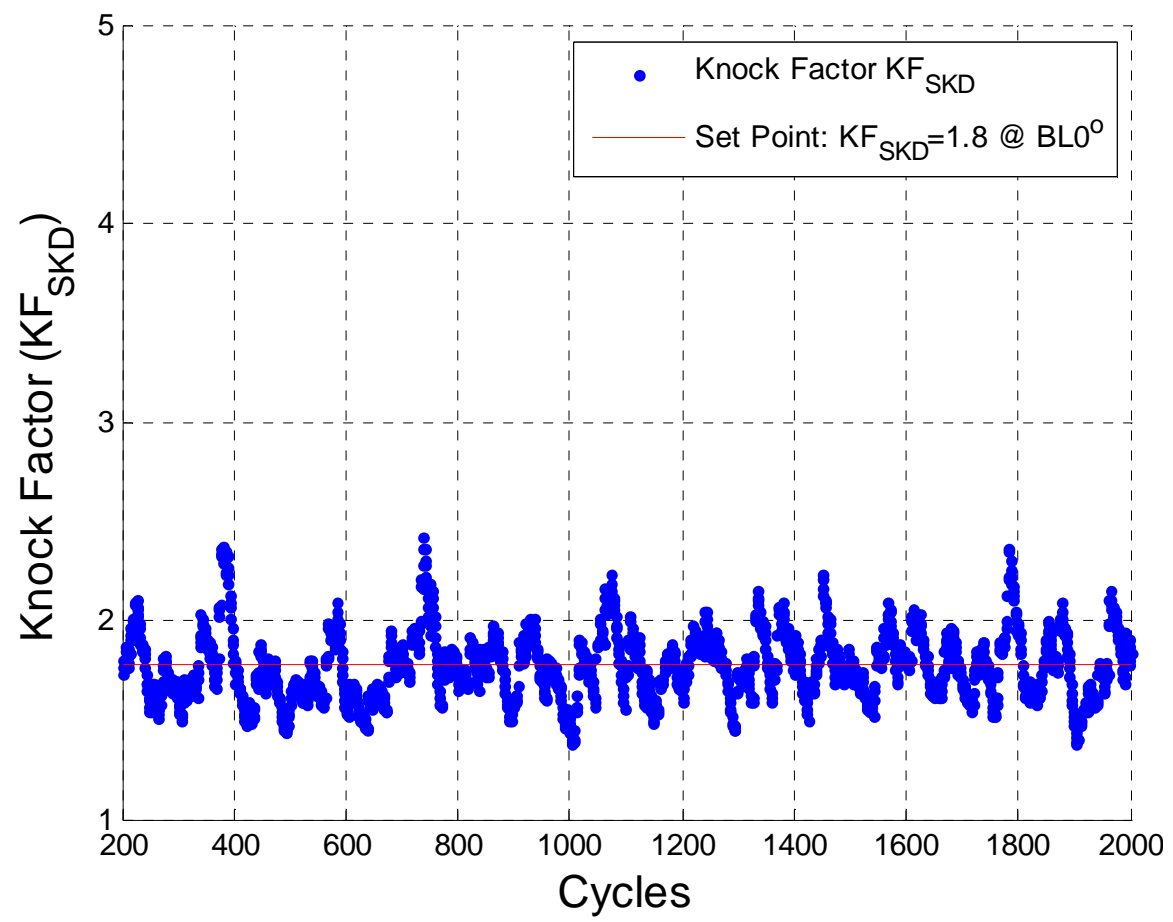

Figure 4-14: Knock Factor in steady state knock control operation at 2000 rpm and WOT for cylinder 7

To study the stead state performance of the knock controller, SKD model was simulated for 2000 cycles with controller enabled after 500 cycles of simulation. Knock Factor values when the controller is disabled or enabled are similar, refer Figure 4-14 above. Also, spark timing is maintained between $+/-0.5^{\circ}$ of $B L 0^{\circ}$, after 500 cycles refer Figure 4-15. Boxplot in Figure 4-16 compares knock intensities at $\mathrm{BLO}^{\circ}$ knock level and those obtained using knock controller to maintain knock level with $+/-0.5$ of $\mathrm{BL}^{\circ}$. Boxplot represents $99 \%$ coverage of knock intensity 
data while red markers are the outliers. The controller was able to obtain steady state knock control as knock intensity spread and outliers are very similar in both the cases.

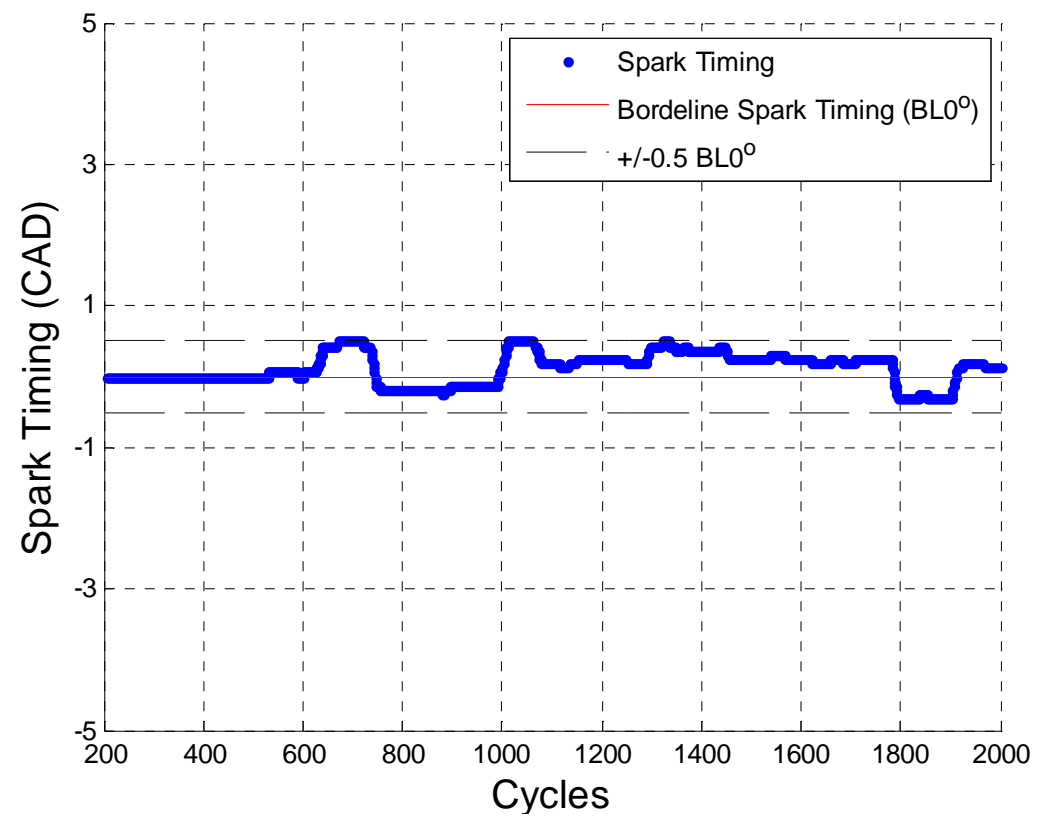

Figure 4-15: Controlled spark timing at borderline knock level $\left(\mathrm{BLO}^{\circ}\right)$ at $2000 \mathrm{rpm}$ and WOT for cylinder 7

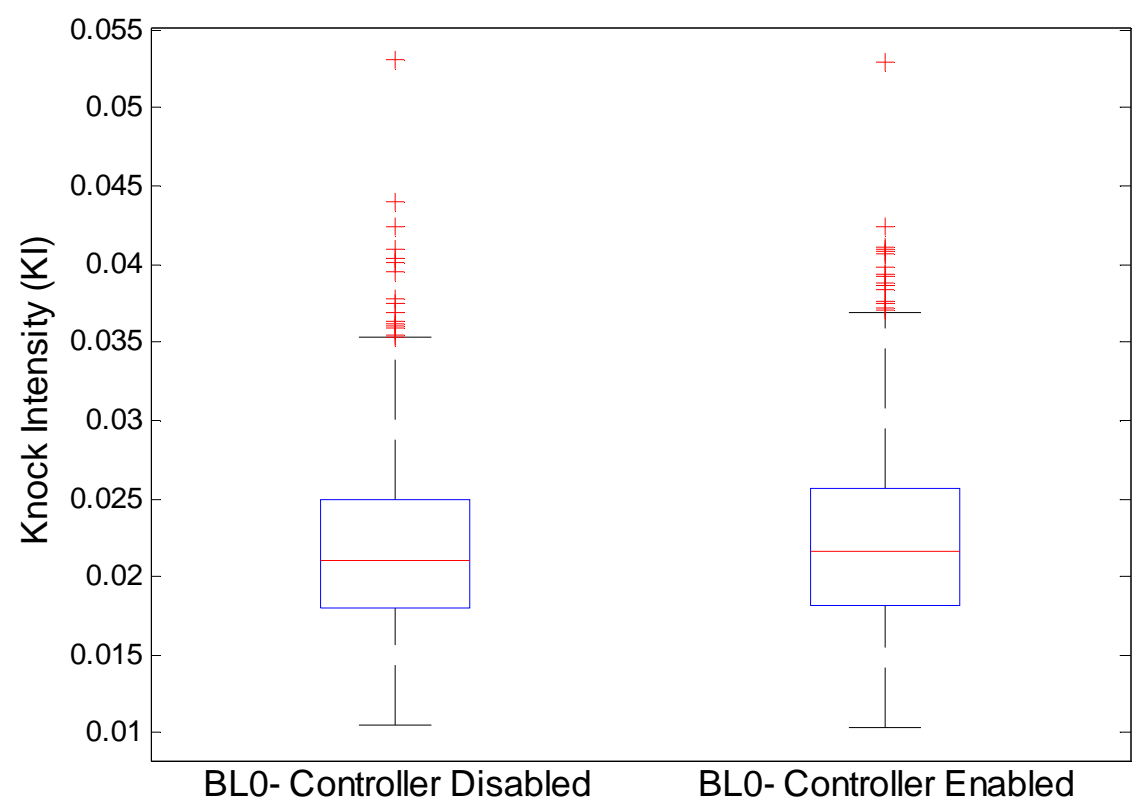

Figure 4-16: Box plot comparing distribution knock intensity KI spreads with controller enabled and disabled case at $2000 \mathrm{rpm}$ and WOT for cylinder 7 .

Page 43 of 56 
Knock control simulation was subjected to a spark timing step input by enabling the knock controller while the knock accelerometer intensity simulator is operating at a knocking condition. The knock control simulation was allowed to operate for 500 simulated engine cycles at a spark advance of $\mathrm{BL}+3^{\circ}$ without the controller module being enabled. After 500 cycles, the control block was enabled and allowed to retard spark until the borderline condition was met.

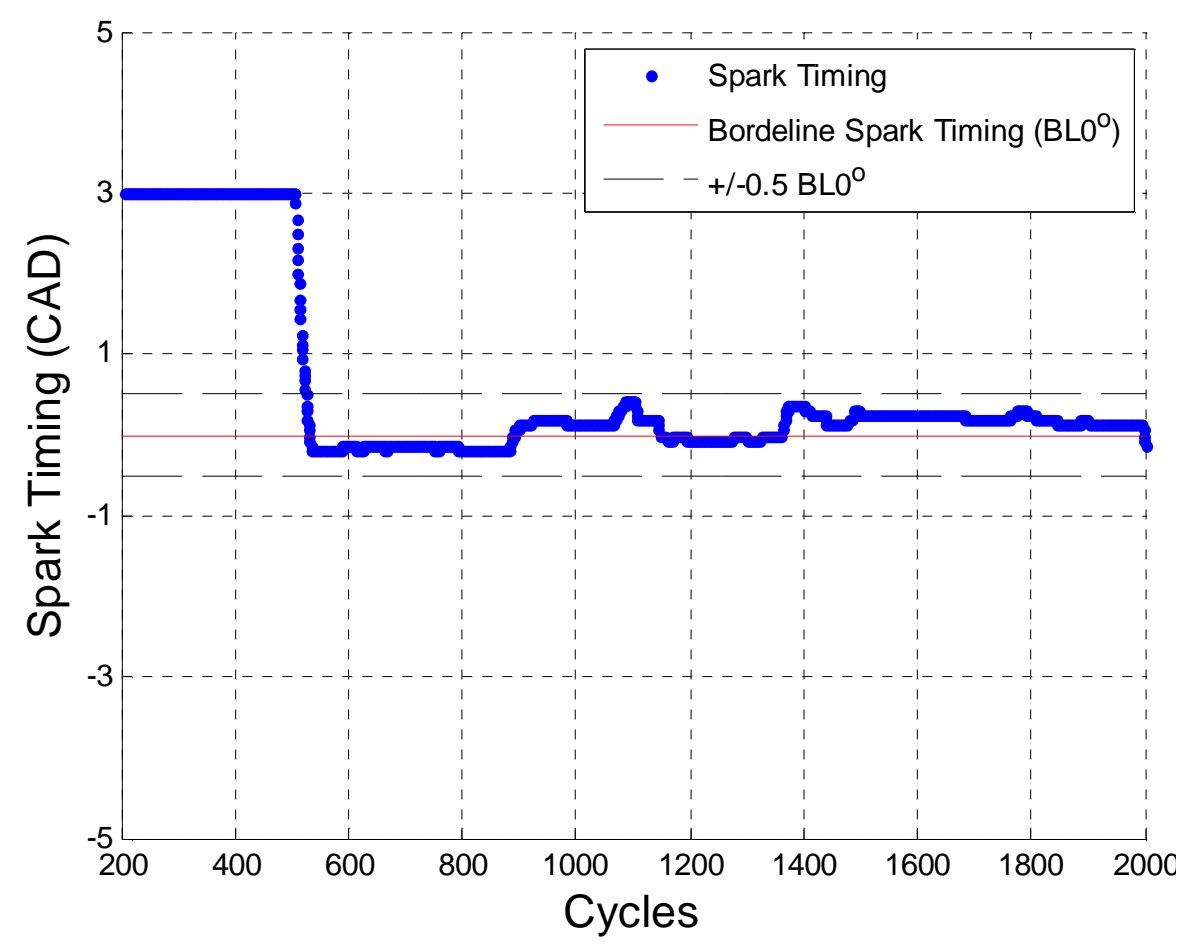

Figure 4-17: Simulated transient spark timing response of knock controller at 2000rpm and WOT for cylinder 7.

The response of a controller designed with integral gains can be seen in Figure 4-17 which displays spark timing response of SKD system after being enabled at cycle number 500 while operating at a spark timing of $\mathrm{BL}+3^{\circ}$. The controller immediately reduces the spark advance by at more than $3^{\circ}$ and reaches the steady state operation band less than 30 engine cycles. Plot of knock factor $\left(\mathrm{KF}_{\mathrm{SKD}}\right)$ which is the control variable is shown in Figure 4-18, before enabling the controller value of $\mathrm{KF}_{\mathrm{SKD}}$ is between 2.5 and 4.5 but after 500 cycles when controller corrects spark timing and maintains $\mathrm{KF}_{\mathrm{SKD}}$ value close to the set-point. 


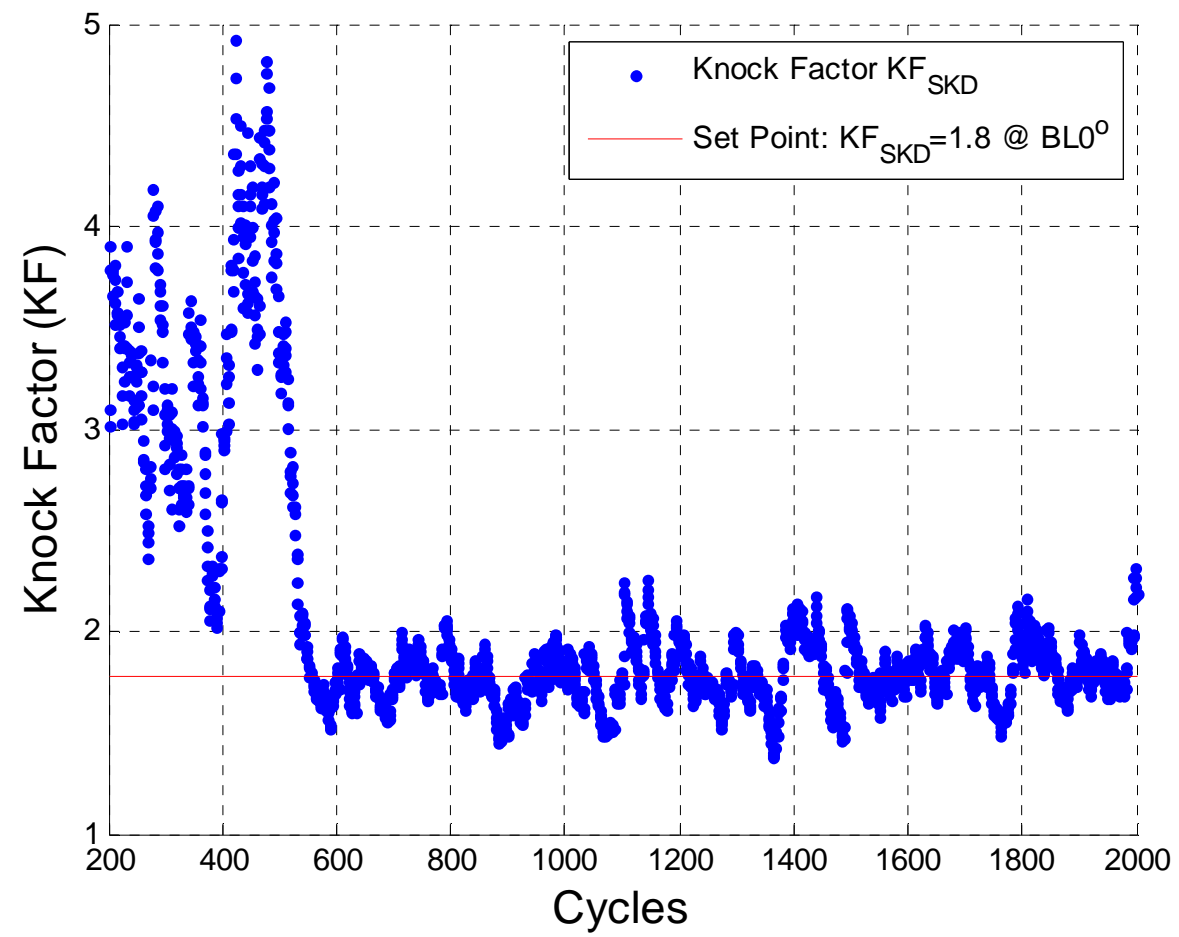

Figure 4-18: Simulated controller response to step input of $\mathrm{BL}+3^{\mathrm{o}}$ at $2000 \mathrm{rpm}$ at WOT for cylinder 7 .

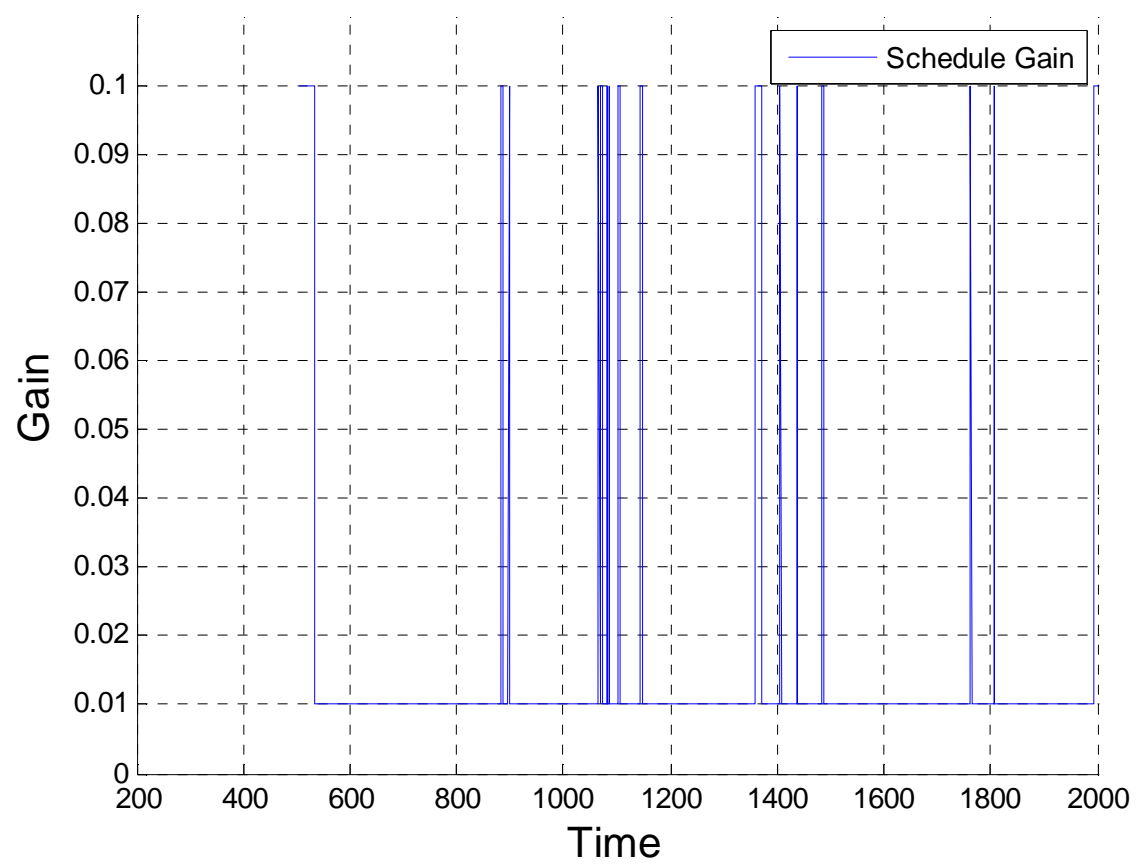

Figure 4-19: Gain Schedule Response 


\section{CHAPTER 5}

\section{SUMMARY AND CONCLUSIONS}

This report covers the development of stochastic knock detection system using model based design. An SKD knock intensity estimation model was created. Multiple knock factors were developed and separation factors were used to evaluate and compare the factors with respect to their accuracy and false positive detection characteristics.

Conclusions from this work include

- Ability to sense knock with SKD knock factor and classic knock detection metric was examined over engine speed range from 1000rpm to 5000rpm. SKD knock factor shows good sensitivity and less variation at given borderline spark advance relative to classic method of knock detection.

- Separation between distributions of SKD knock factor at different spark timing was quantified. SKD method has separation larger than 10 times the separation with classic single window detection method.

- Transient response of 30 point estimator with coefficients weighted to the most recent cycles was found to be 14 cycles to achieve $80 \%$ (T80) of the final value which is deemed acceptable for steady-state response, but maybe to slow for transient operation.

- The transient response can be improved by dynamically adjusting the FIR filter length to a small value which provides better transient response. With an estimator based upon 5 cycles the T80 response is 4 cycles with a separation factor just above one in the sample data.

Future work will be needed to further improve the SKD technology and include the following list.

- Integrate the SKD knock detection into a real-time controller and evaluate on engine. 
- Develop and integrate a knock control system to take advantage of the SKD method and show accuracy and response of the integrated system to control knock under steady-state and dynamic conditions.

- Test the SKD on different engines, at varying engine conditions, and at different disturbance inputs (i.e. load changes).

- Quantify the improvement by determination of reduced fuel consumption. 


\section{REFERENCES}

[1] J. HEYWOOD, (1988), "INTERNAL COMBUSTION ENGINE FUNDAMENTALS."

[2] C. V. F. F. MILLO, "KNOCK IN S.I. ENGINES: A COMPARISON BETWEEN DIFFERENT TECHNIQUES FOR DETECTION AND CONTROL," SAE PAPER 982477, 1998.

[3] P. C. BRUNT M., BIUNDO J, "GASOLINE ENGINE KNOCK ANALYSIS USING CYLINDER PRESSURE DATA," SAE PAPER 980896, 1998.

[4] R. G. SAMIMY B., LEISENRING C.,, "IMPROVED KNOCK DETECTION BY ADVANCED SIGNAL PROCESSING," SAE PAPER, 950845, 1995.

[5] J. D. NABER, RAJAGOPALAN, S.R., "COMBUSTION KNOCK DETECTION AND CONTROL THROUGH STATISTICAL CHARACTERIZATION OF KNOCK LEVELS," US PATENT 2008/0051981 A1, 2008.

[6] J. D. NABER, BLOUGH, J. R., FRANKOWSKI, D., GOBLE, M., AND SZPYTMAN, J.E., "ANALYSIS OF COMBUSTION KNOCK METRICS IN SPARK-IGNITION ENGINES," SAE TRANSACTIONS JOURNAL OF ENGINES, SAE PAPER 2006-010400, 2006.

[7] O. TORNO, HEINSTEIN, A., KLUTH, C., HAEMING, W., "APPARATUS FOR KNOCK DETECTION WITH DIGITAL SIGNAL ANALYSIS AND METHOD OF DETECTING KNOCK USING SAME," US PATENT 6529 817, 2003.

[8] G. BRIELBECK, KLECZKA, W, "METHOD FOR KNOCK REGULATION IN AN INTERNAL COMBUSTION ENGINE," US PATENT 6279 536, 2001.

[9] S. R. RAJAGOPALAN, "DETERMINATION OF COMBUSTION KNOCK INTENSITY IN A SPARK IGNITION ENGINE," MICHIGAN TECHNOLOGICAL UNIVERSITY, HOUGHTON, MI, 2006.

[10] C. S. DRAPER, "THE PHYSICAL EFFECTS OF DETONATION IN A CLOSED CYLINDRICAL CHAMBER," NACA REPORT 493, 1935.

[11] A. S. SOKOLIK, "SELF-IGNITION AND COMBUSTION OF GASES," NACA TECHNICAL MEMORANDUM NO. 1025, 1940. 
[12] L. K. TOWER, AND ALQUIST, H.E, "CORRELATION OF EFFECTS OF FUEL-AIR RATIO, COMPRESSION RATIO, AND INLET-AIR TEMPERATURE ON KNOCK LIMITS OF AVIATION FUELS," NACA TECHNICAL NOTE 2066, 1950.

[13] C. D. MILLER, LOGAN, W.O, "PREKNOCK VIBRATIONS IN A SPARK-IGNITION ENGINE CYLINDER AS REVEALED BY HIGH-SPEED PHOTOGRAPHY," NACA REPORT 785, 1944.

[14] C. D. MILLER, "RELATION BETWEEN SPARK-IGNITION ENGINE KNOCK, DETONATION WAVES, AND AUTOIGNITION AS SHOWN BY HIGH-SPEED PHOTOGRAPHY," NACA REPORT 855, 1946.

[15] H. L. OLSEN, MILLER, C.D, "THE INTERDEPENDENCE OF VARIOUS TYPES OF AUTOIGNITION AND KNOCK," NACA REPORT 912, 1948.

[16] U. KRENCHE, NIELSEN, L. (2000). AUTOMOTIVE CONTROL SYSTEMS.

[17] B. R. (1999). GASOLINE-ENGINE MANAGEMENT.

[18] G. XIAOFENG, STONE,R. HUDSON, C., BRADBURY, I., "THE DETECTION AND QUANTIFICATION OF KNOCK IN SPARK INGITION ENGINES," SAE PAPER 932759, 1993.

[19] E. E. OBERT, "INTERNAL COMBUSTION ENGINES AND AIR POLLUTION," HARPER \& ROW, 1973.

[20] LEPPARD. W. R., "INDIVIDUAL-CYLINDER KNOCK OCCURRENCE AND INTENSITY IN MULTI-CYLINDER ENGINES," SAE 820074, 1982.

[21] K. SINNERSTAD, "KNOCK INTENSITY AND TORQUE CONTROL ON AN SVC ENGINE," MASTER'S THESIS LINKÖPING UNIVERSITY, 2003.

[22] N. ABHIJIT, J.D, "IONIZATION SIGNAL RESPONSE DURING COMBUSTION KNOCK AND COMPARISON TO CYLINDER PRESSURE FOR SI ENGINES," SAE TECHNICAL PAPER 2008-01-0981, 2008.

[23] G. G. ZHU, HASKARA, I., AND WINKELMAN, J., "STOCHASTIC LIMIT CONTROL AND ITS APPLICATION TO KNOCK LIMIT CONTROL USING IONIZATION FEEDBACK," SAE TECHNICAL PAPER 2005-01-0018, 2005.

[24] G. WU, "REAL TIME STATISTICAL METHOD FOR ENGINE KNOCK," SAE TECHNICAL PAPER 2007-01-1507, 2007. 
[25] K. M. PEYTON J. JONES, "A STOCHASTIC KNOCK CONTROL ALGORITHM," SAE PAPER 2009-01-1017, 2009.

[26] C. POLONOWSKI, "STOCHASTIC KNOCK DETECTION PROGRAM: PHASE 2," MICHIGAN TECHNOLOGICAL UNIVERSITY, 2008.

[27] P. W. M. A. K. M. A. ROY E. HUNNINGHAUS, "KNOCK DETECTION METHOD AND APPARATUS WITH DUAL INTEGRATION WINDOWS," US PATENT 5537 855, 1996.

[28] D. C. MONTGOMERY. (2001). DESIGN AND ANALYSIS OF EXPERIMENTS.

\section{ACKNOWLEDGMENTS}

We would like to acknowledge Ford Motor Company and specifically Chris Glugla for the help accorded to us during this project.

\section{DEFINITIONS/ABBREVIATIONS}

RPM: Revolutions per Minute

FIR: Finite Impulse Response

KSS: Knock Signal Simulator

KDM: Knock Detection Model

BL: Borderline

KI: Knock Intensity

KF: Knock Factor

SKD: Stochastic Knock Detection

SF: Separation Factor

BLSA: Borderline Spark Advance

PDF: Probability Distribution Function 


\section{APPENDIX}

\subsection{WEIGHTED MEAN AND STANDARD DEVIATION}

To implement equations 1 and 2 using weighted FIR filters we need to simplify them to derive equations 3, 4 and 5. This will enable the use of different weighting functions to tune response of SKD estimator.

Following is the derivation:

Mean

$$
\mu_{w}=\frac{\sum b_{j} \cdot \ln \left(x_{j}\right)}{\sum b_{j}}=\sum\left(\frac{w_{j}}{\sum w_{j}} \ln \left(x_{j}\right)\right)
$$

If $\sum b_{j}=1$

Thus Weighted Mean

$$
\mu_{w}=\sum\left(\frac{b_{j}}{1} \ln \left(x_{j}\right)\right)=\sum b_{j} \cdot \ln \left(x_{j}\right)
$$

Variance

$$
\sigma^{2}=\frac{\sum b_{j}\left(\ln \left(x_{j}\right)-\mu_{w}\right)^{2}}{(n-1) \bar{b}}
$$

If $\sum b_{j}=1$ then $\bar{b}=\frac{\sum b_{j}}{n}=\frac{1}{n}$

Weighted Variance

$$
\sigma_{w}^{2}=\frac{\sum b_{j}\left(\ln \left(x_{j}\right)-\mu_{w}\right)^{2}}{(n-1) \frac{1}{n}}=\frac{n}{(n-1)} \sum b_{j}\left(\ln \left(x_{j}\right)-\mu_{w}\right)^{2}
$$

Equation 18

Break up Sum of square term:

Summation properties $=>$

$$
b_{j}\left(\ln \left(x_{j}\right)-\mu_{w}\right)^{2}=\sum b_{j} \ln \left(x_{j}\right)^{2}-2 \sum b_{j} \ln \left(x_{j}\right) \mu_{w}+
$$

$\sum b_{j} \mu_{w}^{2}$

Weighted mean is constant $=>$

$$
b_{j}\left(\ln \left(x_{j}\right)-\mu_{w}\right)^{2}=\sum b_{j} \ln \left(x_{j}\right)^{2}-2 \mu_{w} \sum b_{j} \ln \left(x_{j}\right)+
$$

$\mu_{w}^{2} \sum b_{j}$

Page 51 of 56 
Using $\sum b_{j}=1$ and equation $16 \Rightarrow b_{j}\left(\ln \left(x_{j}\right)-\mu_{w}\right)^{2}=\sum b_{j} \ln \left(x_{j}\right)^{2}-2 \mu_{w} \mu_{w}+\mu_{w}^{2}$

Thus we get weighted variance as,

$$
\sigma_{w}^{2}=\frac{n}{(n-1)}\left(\sum b_{j} \ln \left(x_{j}\right)^{2}-\mu_{w}^{2}\right)
$$

Equation 19

\subsection{FORD V8 ENGINE DATA}

Following are the tables for knock intensity mean and standard deviation of Ford V8 engine data.

Table 6: Knock Intensity Mean

\begin{tabular}{|c|c|c|c|c|c|c|}
\hline \multirow{2}{*}{\multicolumn{2}{|c|}{ KI MEAN }} & \multicolumn{5}{|c|}{ Engine Speed (RPM) } \\
\hline & & 1000 & 2000 & 3000 & 4000 & 5000 \\
\hline & & \multicolumn{5}{|c|}{ Cylinder 1} \\
\hline \multirow{8}{*}{ 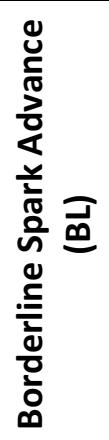 } & -4.00 & -5.32 & -3.84 & -3.01 & -2.84 & -2.52 \\
\hline & -3.00 & -5.13 & -3.76 & -3.00 & -2.81 & -2.53 \\
\hline & -2.00 & -4.96 & -3.72 & -3.00 & -2.68 & -2.50 \\
\hline & -1.00 & -4.65 & -3.70 & -3.09 & -2.66 & -2.47 \\
\hline & 0.00 & -4.16 & -3.64 & -3.18 & -2.66 & -2.34 \\
\hline & 1.00 & -3.65 & -3.58 & -3.14 & -2.66 & -2.27 \\
\hline & 2.00 & -2.99 & -3.55 & -3.15 & -2.66 & -2.31 \\
\hline & 3.00 & & -3.38 & -3.10 & -2.66 & -2.28 \\
\hline \multirow{9}{*}{ 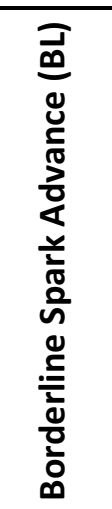 } & & \multicolumn{5}{|c|}{ Cylinder 2} \\
\hline & -4.00 & -5.26 & -4.45 & -3.70 & -3.30 & -2.76 \\
\hline & -3.00 & -5.15 & -4.40 & -3.70 & -3.28 & -2.79 \\
\hline & -2.00 & -5.05 & -4.31 & -3.59 & -3.27 & -2.76 \\
\hline & -1.00 & -4.92 & -4.33 & -3.63 & -3.25 & -2.66 \\
\hline & 0.00 & -4.55 & -4.33 & -3.53 & -3.26 & -2.61 \\
\hline & 1.00 & -3.96 & -4.27 & -3.44 & -3.18 & -2.58 \\
\hline & 2.00 & -3.69 & -4.10 & -3.32 & -3.12 & -2.54 \\
\hline & 3.00 & & -3.85 & -3.07 & -3.07 & -2.52 \\
\hline \multirow{5}{*}{ 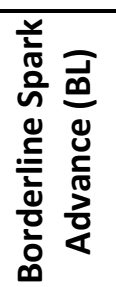 } & & \multicolumn{5}{|c|}{ Cylinder 3} \\
\hline & -4.00 & -5.13 & -4.05 & -3.43 & -3.11 & -2.51 \\
\hline & -3.00 & -5.02 & -4.03 & -3.39 & -3.12 & -2.53 \\
\hline & -2.00 & -4.78 & -3.99 & -3.44 & -3.14 & -2.55 \\
\hline & -1.00 & -4.62 & -3.95 & -3.42 & -3.15 & -2.59 \\
\hline
\end{tabular}

Page 52 of 56 


\begin{tabular}{|c|c|c|c|c|c|c|}
\hline & 0.00 & -4.29 & -3.87 & -3.36 & -3.11 & -2.58 \\
\hline & 1.00 & -3.87 & -3.83 & -3.38 & -3.11 & -2.60 \\
\hline & 2.00 & -3.50 & -3.82 & -3.19 & -3.07 & -2.62 \\
\hline & 3.00 & & -3.55 & -3.16 & -3.00 & -2.51 \\
\hline \multirow{9}{*}{ 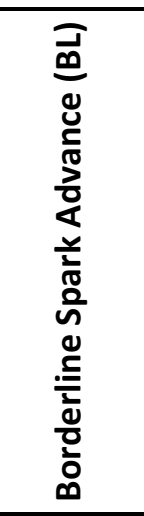 } & & \multicolumn{5}{|c|}{ Cylinder 4} \\
\hline & -4.00 & -5.44 & -4.42 & -3.87 & -2.64 & -2.33 \\
\hline & -3.00 & -5.21 & -4.37 & -3.81 & -2.69 & -2.30 \\
\hline & -2.00 & -5.06 & -4.34 & -3.81 & -2.71 & -2.32 \\
\hline & -1.00 & -4.86 & -4.31 & -3.75 & -2.75 & -2.33 \\
\hline & 0.00 & -4.47 & -4.26 & -3.65 & -2.76 & -2.41 \\
\hline & 1.00 & -4.25 & -4.15 & -3.66 & -2.81 & -2.34 \\
\hline & 2.00 & -3.58 & -4.11 & -3.49 & -2.73 & -2.27 \\
\hline & 3.00 & & -3.80 & -3.33 & -2.75 & -2.25 \\
\hline \multirow{9}{*}{ 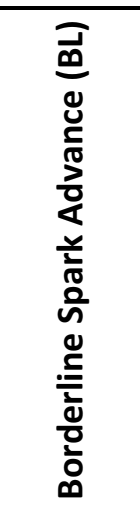 } & & \multicolumn{5}{|c|}{ Cylinder 5} \\
\hline & -4.00 & -5.21 & -4.34 & -3.79 & -3.29 & -2.81 \\
\hline & -3.00 & -5.14 & -4.39 & -3.78 & -3.26 & -2.80 \\
\hline & -2.00 & -5.17 & -4.35 & -3.78 & -3.27 & -2.79 \\
\hline & -1.00 & -4.80 & -4.36 & -3.77 & -3.28 & -2.78 \\
\hline & 0.00 & -4.23 & -4.23 & -3.67 & -3.20 & -2.79 \\
\hline & 1.00 & -3.82 & -4.12 & -3.64 & -3.19 & -2.77 \\
\hline & 2.00 & -3.45 & -3.95 & -3.51 & -3.20 & -2.68 \\
\hline & 3.00 & & -3.75 & -3.43 & -3.11 & -2.67 \\
\hline \multirow{9}{*}{ 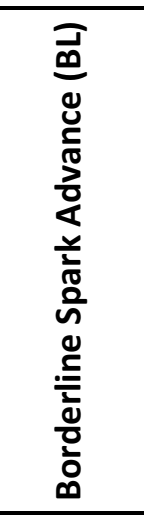 } & & \multicolumn{5}{|c|}{ Cylinder 6} \\
\hline & -4.00 & -5.11 & -4.18 & -3.34 & -2.93 & -2.41 \\
\hline & -3.00 & -5.02 & -4.19 & -3.37 & -2.96 & -2.48 \\
\hline & -2.00 & -4.88 & -4.16 & -3.33 & -2.98 & -2.43 \\
\hline & -1.00 & -4.75 & -4.16 & -3.30 & -2.96 & -2.37 \\
\hline & 0.00 & -4.36 & -4.09 & -3.26 & -2.98 & -2.36 \\
\hline & 1.00 & -3.79 & -4.02 & -3.16 & -2.91 & -2.37 \\
\hline & 2.00 & -3.39 & -3.78 & -3.22 & -2.90 & -2.39 \\
\hline & 3.00 & & -3.50 & -3.06 & -2.89 & -2.32 \\
\hline \multirow{4}{*}{ 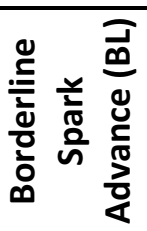 } & & \multicolumn{5}{|c|}{ Cylinder 7} \\
\hline & -4.00 & -5.46 & -4.05 & -3.53 & -2.97 & -2.53 \\
\hline & -3.00 & -5.28 & -4.00 & -3.48 & -2.94 & -2.44 \\
\hline & -2.00 & -5.22 & -3.98 & -3.50 & -2.92 & -2.43 \\
\hline
\end{tabular}

Page 53 of 56 


\begin{tabular}{|c|c|c|c|c|c|c|}
\hline & -1.00 & -5.06 & -3.92 & -3.48 & -2.91 & -2.40 \\
\hline & 0.00 & -4.52 & -3.85 & -3.42 & -2.89 & -2.45 \\
\hline & 1.00 & -4.12 & -3.72 & -3.31 & -2.88 & -2.47 \\
\hline & 2.00 & -3.76 & -3.50 & -3.19 & -2.81 & -2.47 \\
\hline & 3.00 & & -3.22 & -3.01 & -2.72 & -2.39 \\
\hline \multirow{9}{*}{ 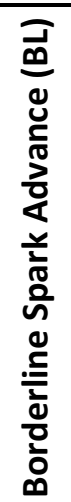 } & & \multicolumn{5}{|c|}{ Cylinder 8} \\
\hline & -4.00 & -5.60 & -4.39 & -3.52 & -3.28 & -2.32 \\
\hline & -3.00 & -5.59 & -4.35 & -3.50 & -3.24 & -2.31 \\
\hline & -2.00 & -5.41 & -4.32 & -3.54 & -3.25 & -2.32 \\
\hline & -1.00 & -5.22 & -4.29 & -3.46 & -3.22 & -2.33 \\
\hline & 0.00 & -4.73 & -4.27 & -3.45 & -3.20 & -2.37 \\
\hline & 1.00 & -4.28 & -4.15 & -3.42 & -3.18 & -2.37 \\
\hline & 2.00 & -3.75 & -3.80 & -3.36 & -3.13 & -2.41 \\
\hline & 3.00 & & -3.56 & -3.28 & -3.08 & -2.37 \\
\hline
\end{tabular}

Table 7: Knock Intensity Standard Deviation

\begin{tabular}{|c|c|c|c|c|c|c|}
\hline \multirow{2}{*}{\multicolumn{2}{|c|}{ KI STD }} & \multicolumn{5}{|c|}{ Engine Speed (RPM) } \\
\hline & & 1000 & 2000 & 3000 & 4000 & 5000 \\
\hline \multirow{9}{*}{ 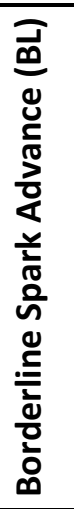 } & & \multicolumn{5}{|c|}{ Cylinder 1} \\
\hline & -4 & 0.248034 & 0.180473 & 0.130474 & 0.157801 & 0.242029 \\
\hline & -3 & 0.308955 & 0.168799 & 0.135295 & 0.175189 & 0.249997 \\
\hline & -2 & 0.359741 & 0.158744 & 0.141946 & 0.167073 & 0.256819 \\
\hline & -1 & 0.515763 & 0.172104 & 0.175826 & 0.180499 & 0.286147 \\
\hline & 0 & 0.659114 & 0.166791 & 0.191679 & 0.182756 & 0.276044 \\
\hline & 1 & 0.740177 & 0.21404 & 0.210808 & 0.183676 & 0.284864 \\
\hline & 2 & 0.653761 & 0.273337 & 0.272756 & 0.182687 & 0.277891 \\
\hline & 3 & & 0.377088 & 0.33154 & 0.201025 & 0.28578 \\
\hline \multirow{9}{*}{ 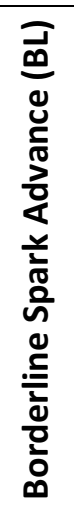 } & & \multicolumn{5}{|c|}{ Cylinder 2} \\
\hline & -4 & 0.149974 & 0.146713 & 0.184611 & 0.178234 & 0.20606 \\
\hline & -3 & 0.193275 & 0.141474 & 0.163387 & 0.18653 & 0.208148 \\
\hline & -2 & 0.227243 & 0.161308 & 0.181966 & 0.193871 & 0.216492 \\
\hline & -1 & 0.298554 & 0.166479 & 0.192058 & 0.178684 & 0.2129 \\
\hline & 0 & 0.37008 & 0.210539 & 0.223952 & 0.179608 & 0.212583 \\
\hline & 1 & 0.474131 & 0.223914 & 0.279319 & 0.196835 & 0.223338 \\
\hline & 2 & 0.505545 & 0.309705 & 0.368339 & 0.190079 & 0.235356 \\
\hline & 3 & & 0.408855 & 0.455475 & 0.265466 & 0.303976 \\
\hline
\end{tabular}

Page 54 of 56 


\begin{tabular}{|c|c|c|c|c|c|c|}
\hline \multirow{9}{*}{ 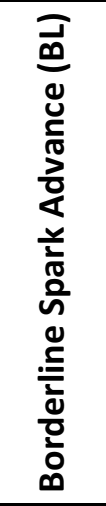 } & & \multicolumn{5}{|c|}{ Cylinder 3} \\
\hline & -4 & 0.245268 & 0.143961 & 0.16306 & 0.188901 & 0.200131 \\
\hline & -3 & 0.278921 & 0.164821 & 0.178142 & 0.191851 & 0.208418 \\
\hline & -2 & 0.328537 & 0.160317 & 0.179973 & 0.186409 & 0.211494 \\
\hline & -1 & 0.359449 & 0.158784 & 0.199796 & 0.194985 & 0.212357 \\
\hline & 0 & 0.417397 & 0.184528 & 0.196731 & 0.184514 & 0.214499 \\
\hline & 1 & 0.48896 & 0.191772 & 0.254227 & 0.215533 & 0.237501 \\
\hline & 2 & 0.511034 & 0.303907 & 0.349372 & 0.261018 & 0.286739 \\
\hline & 3 & & 0.428844 & 0.394651 & 0.289411 & 0.335716 \\
\hline \multirow{9}{*}{ 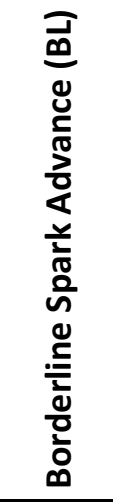 } & & \multicolumn{5}{|c|}{ Cylinder 4} \\
\hline & -4 & 0.228491 & 0.183818 & 0.188225 & 0.129827 & 0.160496 \\
\hline & -3 & 0.24155 & 0.170156 & 0.205131 & 0.133213 & 0.158382 \\
\hline & -2 & 0.31743 & 0.181366 & 0.204651 & 0.131776 & 0.188975 \\
\hline & -1 & 0.373687 & 0.181068 & 0.210387 & 0.142027 & 0.19842 \\
\hline & 0 & 0.535765 & 0.189218 & 0.23194 & 0.146071 & 0.209094 \\
\hline & 1 & 0.541034 & 0.26122 & 0.247589 & 0.146121 & 0.186862 \\
\hline & 2 & 0.531198 & 0.377938 & 0.291182 & 0.153721 & 0.204664 \\
\hline & 3 & & 0.456463 & 0.400576 & 0.169706 & 0.201741 \\
\hline \multirow{9}{*}{ 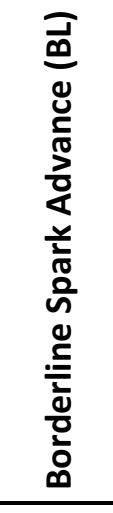 } & & \multicolumn{5}{|c|}{ Cylinder 5} \\
\hline & -4 & 0.235843 & 0.175416 & 0.164486 & 0.180789 & 0.218169 \\
\hline & -3 & 0.240892 & 0.179639 & 0.182913 & 0.209378 & 0.207508 \\
\hline & -2 & 0.306501 & 0.175063 & 0.16222 & 0.189776 & 0.222951 \\
\hline & -1 & 0.376733 & 0.196685 & 0.164292 & 0.205542 & 0.232445 \\
\hline & 0 & 0.513659 & 0.213177 & 0.176709 & 0.191086 & 0.215588 \\
\hline & 1 & 0.547901 & 0.28981 & 0.24047 & 0.19174 & 0.209994 \\
\hline & 2 & 0.532162 & 0.368868 & 0.316293 & 0.216835 & 0.225049 \\
\hline & 3 & & 0.462399 & 0.369935 & 0.254641 & 0.248837 \\
\hline \multirow{8}{*}{ 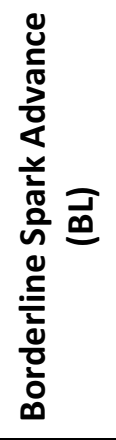 } & & \multicolumn{5}{|c|}{ Cylinder 6} \\
\hline & -4 & 0.31754 & 0.161939 & 0.175008 & 0.149681 & 0.15298 \\
\hline & -3 & 0.300858 & 0.191594 & 0.168882 & 0.145044 & 0.161553 \\
\hline & -2 & 0.317675 & 0.180336 & 0.177834 & 0.145835 & 0.166728 \\
\hline & -1 & 0.376959 & 0.206256 & 0.166596 & 0.154561 & 0.151942 \\
\hline & 0 & 0.492425 & 0.246135 & 0.178451 & 0.15888 & 0.16338 \\
\hline & 1 & 0.541203 & 0.303863 & 0.259059 & 0.161268 & 0.156776 \\
\hline & 2 & 0.508736 & 0.434188 & 0.320657 & 0.187872 & 0.202451 \\
\hline
\end{tabular}

Page 55 of 56 


\begin{tabular}{|c|c|c|c|c|c|c|}
\hline & 3 & & 0.536146 & 0.406912 & 0.219538 & 0.198408 \\
\hline \multirow{9}{*}{ 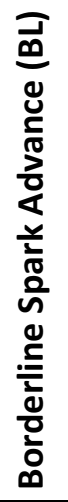 } & & \multicolumn{5}{|c|}{ Cylinder 7} \\
\hline & -4 & 0.25362 & 0.18152 & 0.193075 & 0.193681 & 0.239201 \\
\hline & -3 & 0.297318 & 0.172751 & 0.180582 & 0.175085 & 0.195199 \\
\hline & -2 & 0.326119 & 0.192331 & 0.189993 & 0.187488 & 0.209737 \\
\hline & -1 & 0.420625 & 0.214429 & 0.208845 & 0.199829 & 0.202505 \\
\hline & 0 & 0.487668 & 0.240602 & 0.249366 & 0.191636 & 0.230862 \\
\hline & 1 & 0.531621 & 0.313761 & 0.392482 & 0.217127 & 0.230966 \\
\hline & 2 & 0.568141 & 0.449289 & 0.441939 & 0.256358 & 0.311494 \\
\hline & 3 & & 0.543746 & 0.538889 & 0.311586 & 0.335584 \\
\hline \multirow{9}{*}{ 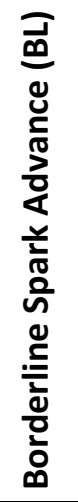 } & & \multicolumn{5}{|c|}{ Cylinder 8} \\
\hline & -4 & 0.165506 & 0.238376 & 0.171462 & 0.161421 & 0.167698 \\
\hline & -3 & 0.189365 & 0.238363 & 0.180019 & 0.153561 & 0.174817 \\
\hline & -2 & 0.262785 & 0.208981 & 0.167122 & 0.15756 & 0.165394 \\
\hline & -1 & 0.341114 & 0.207798 & 0.203062 & 0.173447 & 0.167647 \\
\hline & 0 & 0.463113 & 0.244302 & 0.215618 & 0.163285 & 0.187666 \\
\hline & 1 & 0.517977 & 0.368372 & 0.212896 & 0.181012 & 0.206655 \\
\hline & 2 & 0.560514 & 0.423521 & 0.231714 & 0.19476 & 0.227745 \\
\hline & 3 & & 0.512936 & 0.323755 & 0.244437 & 0.269502 \\
\hline
\end{tabular}

